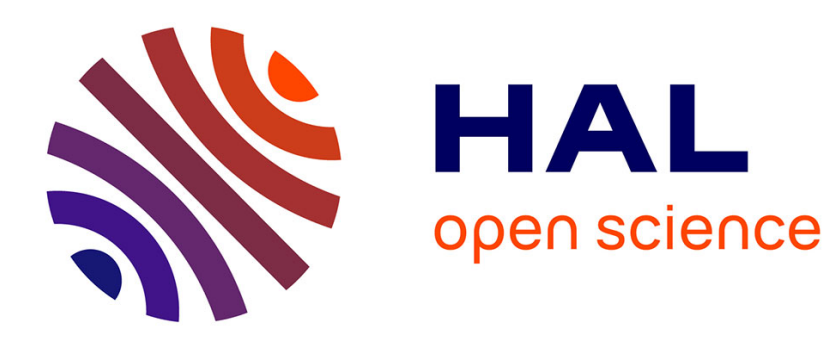

\title{
Participating insurance contracts and the Rothschild-Stiglitz equilibrium puzzle
}

Pierre Picard

\section{To cite this version:}

Pierre Picard. Participating insurance contracts and the Rothschild-Stiglitz equilibrium puzzle. 2009. hal-00413825

\section{HAL Id: hal-00413825 \\ https://hal.science/hal-00413825}

Preprint submitted on 7 Sep 2009

HAL is a multi-disciplinary open access archive for the deposit and dissemination of scientific research documents, whether they are published or not. The documents may come from teaching and research institutions in France or abroad, or from public or private research centers.
L'archive ouverte pluridisciplinaire HAL, est destinée au dépôt et à la diffusion de documents scientifiques de niveau recherche, publiés ou non, émanant des établissements d'enseignement et de recherche français ou étrangers, des laboratoires publics ou privés. 


\section{ECOLE POLYTECHNIQUE}

CENTRE NATIONAL DE LA RECHERCHE SCIENTIFIQUE

\section{PARTICIPATING INSURANCE CONTRACTS AND THE ROTHSCHILD-STIGLITZ EQUILIBRIUM PUZZLE}

Pierre PICARD

July 2009

Cahier $n^{\circ}$ 2009-30

\section{DEPARTEMENT D'ECONOMIE}

Route de Saclay

91128 PALAISEAU CEDEX

(33) 169333033

http://www.enseignement.polytechnique.fr/economie/

mailto:chantal.poujouly@polytechnique.edu 


\title{
PARTICIPATING INSURANCE CONTRACTS AND THE ROTHSCHILD-STIGLITZ EQUILIBRIUM PUZZLE
}

\author{
Pierre PICARD ${ }^{1}$
}

July 2009

Cahier $n^{\circ}$ 2009-30

\begin{abstract}
We show that an equilibrium always exists in the Rothschild-Stiglitz insurance market model with adverse selection when insurers can offer either non- participating or participating policies, i.e. insurance contracts which may involve policy dividends or supplementary calls for premium. The equilibrium coincides with the MiyazakiSpence-Wilson equilibrium, which may involves cross-subsidization between contracts within subgroups of individuals. The paper establishes that participating policies act as an implicit threat that dissuades deviant insurers who aim at attracting low risk individuals only. The model predicts that the mutual corporate form should be prevalent in insurance markets or submarkets where second-best Pareto efficiency requires cross-subsidization between risk types. Stock insurers and mutuals may coexist, with stock insurers offering insurance coverage at actuarial price and mutuals cross-subsidizing risks.
\end{abstract}

\footnotetext{
${ }^{1}$ Ecole Polytechnique, Department of Economics; Email: pierre.picard@polytechnique.edu
} 


\section{Introduction}

The paper of Rothschild and Stiglitz (1976) on competitive insurance markets under adverse selection is widely considered as one of the most important contributions to the insurance economics literature. In this famous article, Rothschild and Stiglitz analyse the equilibrium of an insurance market where policyholders have private information on their risk and they reveal this information through their insurance contract choice. High risk individuals choose to be fully covered, while low risks choose partial coverage. In other words, the menu of contracts offered in the market separates risk types. The influence of the Rothschild-Stiglitz paper on the academic research in insurance economics has been and is still extremely important. In particular, it shows how hidden information may lead to efficiency losses in markets that satisfy all the axioms of perfect competition except transparency. As a consequence, the Rothschild-Stiglitz approach yields a way to understand why insurance markets are so deeply associated with contractual or legal mechanisms that reduce the intensity or the consequences of hidden information, such as risk categorization, risk auditing or experience rating.

The Rothschild-Stiglitz (RS) model nevertheless includes an enigma that has puzzled and annoyed many insurance economists during the last three decades : in this model, the market equilibrium may not exist! When it is assumed that each insurer only offers a single contract there is no pooling equilibrium, at which all individuals would take out the same contract offered by all insurers. Indeed, at a candidate pooling equilibrium insurers make zero profit, but any insurer can deviate to a profitable contract with lower coverage and lower premium by attracting only low risk individuals. Thus the only type of equilibrium that may exist is separating, with high risks and low risks choosing different contracts. However, it turns out that a separating equilibrium only exists when the population includes a subtantial proportion of high risk individuals. That may be easily understood. Indeed separating risk types entails a welfare loss for low risk individuals, since they should be offered a contract with low coverage, so that high risk individuals prefer a full insurance contract at high actuarial price rather than mimicking low risk individuals. However, when the proportion of high risks is low enough, insurers may make profit by deviating from this separating allocation to another contract that would attract high risks and low risks simultaneously. In other words, a pooling equilibrium never exists because of the profitable cream skimming strategy and a separating equilibrium neither exists when the weight of low risk individuals is too small to let high risks incur the welfare loss associated with the separation of risk types. As observed by Rothschild and Stiglitz (1976) themselves, allowing each insurer to offer a menu of contracts makes the condition under which an equilibrium exists even more restrictive. Indeed, no equilibrium with cross-susbsidization can exist, for obviously each insurer would prefer to delete the contract in deficit. Any candidate equilibrium is separating without cross-subsidization 
and the contracts offered at such a candidate equilibrium coincide with those offered at the separating equilibrium when each insurer only offers one single contract: high risk individuals are fully covered, while low risk individual purchase partial insurance. However such an equilibrium exists only if the separating allocation is not Paretodominated by a menu of contracts with cross-subsidization, which once again requires the proportion of high risk individuals to be large enough. The proportion of high risk individuals under which the equilibrium does not exist is larger when each insurance company offers a menu than when it only offers a single contract. In other words, allowing insurers to offer a menu does not change the candidate separating allocation, but it makes the existence of equilibrium even less likely.

Rather than a theoretical oddity, a model without equilibrium is like a map with terra incognita showing some unexplored territories. In other words, observing that no equilibrium may exist is just a way to acknowledge that the model does not always predict where market forces are leading us. In game theory words, an equilibrium of the $\mathrm{RS}$ model is a subgame perfect Nash equilibrium of a two stage game, in which insurers simultaneously offer insurance contracts at stage 1 and then at stage 2 individuals choose the contract they prefer in the menu of available offers. Most theorists who have tackled the equilibrium nonexistence problem have strayed away from this simple and most natural timing. The "anticipatory equilibrium" of Miyazaki (1977), Spence (1978) and Wilson (1977), the "reactive equilibrium" of Riley (1979) and the variations on the equilibrium concept introduced by Hellwig (1987) and Engers and Fernandez (1987) share this common strategy, which consists in introducing some interactive dynamics among insurers. The existence of equilibrium can then be established, but at the cost of much arbitraryness in the structure of the game and thus of its predictions.

In this paper we will head in a different direction by focusing attention on the nature of contracts which are traded in the insurance market. It is indeed striking to observe that almost all the papers which have focused attention on the equilibrium existence issue seem to have taken for granted that the insurance contracts should take the simple form of non-participating contracts postulated by Rothschild and Stiglitz (1976) and this simple form only. A non-participating insurance contract specifies a fixed premium and an indemnity to be paid should a loss occurs. Even if we do not modify on any other aspect the setting of the RS model (a one period market with all insurers playing simultaneously, two types of risk averse individuals, losses of given size in case of an accident, etc...), we should at least keep in mind that insurers may also offer participating contracts, i.e. contracts with policy dividend when risk underwriting proved to be profitable and supplementary call when it was in deficit. After all, in the real world, mutuals and sometimes stock insurers offer participating contracts $^{1}$. Focusing attention on non-participating contracts only amounts to restricting

\footnotetext{
${ }^{1}$ The mutual market share at the end of 2006 was $24 \%$ (and $28 \%$ for non-life business). Of the largest ten insurance countries, representing $78 \%$ of the world market, five of them have over $25 \%$ of their markets in mutual and cooperative business, namely Germany 41\%, France 40\%; Japan 36\%, USA 30\% and Spain 29\%. See www.icmif.org on the activity of the cooperative and mutual insurance
} 
the shape of insurance contracts in an unjustified way. As we will see in this paper, eliminating this restriction on contractual arrangements restores the existence of the equilibrium in the RS model.

It would be unfair not to acknowledge the contribution of the few papers that have addressed the role of mutuals offering participating contracts in the RS environnement. Boyd, Prescott and Smith (1988) have used a cooperative game theoretic approach in which individuals are viewed as forming coalitions for the purpose of pooling risk. Any coalition decides upon an "arrangement" that specifies the risk sharing within the coalition, as a function of its membership. A coalition may be interpreted as a mutual and an arrangement as a participating contract. Boyd, Prescott and Smith (1988) show that the Miyazaki-Spence-Wilson (MSW) equilibrium allocation ${ }^{2}$ is a core arrangement associated with an unblocked incumbent (grand) coalition that would include all individuals. However they do not analyse the competition between mutuals. By contrast, the present paper shows that the MSW allocation can be sustained as a subgame perfect equilibrium of a non-cooperative game played by insurers who interact with individual agents in a competitive market. Smith and Stutzer (1990) analyse how participating policies serve as a self-selection device when there is exogenous aggregate uncertainty. They interpret mutuals as insurance firms that share undiversifiable aggregate risk with policyholders through participating contract, contrary to stock insurers who share this risk with shareholders. However they do not observe that a pooling equilibrium may occur under participating contracts, and consequently they do not say anything about equilibrium existence issues. Ligon and Thistle (2005) study the coexistence between mutuals or between mutuals and stock insurers They show that, under certain conditions, a separating equilibrium exists in which high risks form large mutuals and low risks form small mutuals. The conditions under which this separating equilibrium exists are analogous to those under which a separating equilibrium exists in the standard RS model.

sector worldwide. Mutuals usually charge their members a premium, known as an advance call, at the start of each policy period. However, they have the right to charge additional premium, known as a supplementary call, if they need additional income to pay claims or increase the reserves. They may also refund part of the advance call if the fortunes of the financial year are better than expected. Note however that the present paper will conclude that policy dividends and supplementary calls act as implicit threats against competitors, which does not mean that they should be frequently observed in practice. After all efficient threats have not to be carried out ! We should also keep in mind that mutuals smooth the distribution of surpluses and the allocation of shortfalls between participating members by making transfers to or from their reserves. In other words, mutuals also act as an intertemporal resource allocation mechanism. Mutuals will ask the participating members for a supplementary call when liabilities exceed assets. When assets exceed liabilities, then the balance may be either transferred to the mutual's reserve or returned to the members, which is usually done in proportion of their respective premiums and subscriptions. See Section 5 on deferred premium variations as substitutes to policy dividends and supplementary calls.

${ }^{2}$ When there are two risk types, the Miyazaki-Spence-Wilson allocation maximizes the expected utility of low risk individuals in the set of second-best feasible allocations, i.e. allocations that break even on aggregate and satisfy incentive compatibility constraints. 
The central argument of this paper may be set out in a few words. In our model, when there is cross-subsidization between risk types, participating policies act as an implicit threat against deviant insurers who would like to attract low risks only. This is actually a very intuitive result. Indeed, assume that high risk individuals have taken out a participating policy which is cross-subsidized by low risk individuals. In such a case, when low risk types move to another insurer, the situation of high risk types deteriorates (because of the participating nature of their insurance contract), which means that it is more difficult for the deviant insurer to attract low risk individuals without attracting also high risk individuals. An equilibrium with cross-subsidization is thus possible because of this implicit threat. Our model thus predicts that we should observe participating contracts when there is cross-subsidization between risk types, and non-participating contracts otherwise ${ }^{3}$. In the two risk type case, allocations with cross-subsidization Pareto-dominate the Rosthchild-Stiglitz pair of contracts when the proportion of large risks is small. In that case there is no equilibrium in the Rothschild-Stiglitz model with non-participating contracts, while an equilibrium with cross-subsidized participating contracts actually exists. Since participating contracts are mainly offered by mutuals, and non-participating contracts by stock insurers ${ }^{4}$, we deduce that the mutual corporate form should be prevalent in markets or segments of markets with cross-subsidization between risk types, while there should be stock insurers (and possibly also mutuals) in other cases.

The model is presented in Section 2, with a brief reminder of the RS model. Sections 3 and 4 characterize the market equilibrium when insurers can offer participating or non-participating contracts. Section 3 restricts attention to the two-risk type case, as in the RS model. It starts with the most simple case where each insurer is supposed to offer only one contract, and then it considers the more realistic setting where each insurer can offer several contracts (say a menu of insurance policies). Most developments in Section 3 are based on figures, with an intuitive game theory framework. Section 4 extends our results to the case of an arbitrary number of risk types, within a more formal game theory setting. In this Section, we first introduce the market game, which is a two stage game where insurers offer menus of (participating or nonparticipating) contracts at stage 1 , and individuals react at stage 2 by choosing the contract they prefer among the offers available in the market. An equilibrium allocation is sustained by a subgame perfect Nash equilibrium of the market game. We

\footnotetext{
${ }^{3}$ More precisely, it turns out that participating contracts are of particular interest when risk crosssubsidization improves the efficiency in insurance markets. Otherwise, non-participating contracts do the job as well. Note also that no policy dividend is paid and no supplementary call is made on the equilibrium path of our model. In other words, these are implicit threats which are not carried out at equilibrium. In practice, more often than not, mutuals pay policy dividends or call for supplementary contributions when some unexpected factor affects the return on their assets or invalidates their loss assumptions.

${ }^{4}$ This distinction is valid for property-casualty insurance. Stock insurers also offer participating life insurance contracts.
} 
define a candidate equilibrium allocation as done by Spence (1978) in his extension of the Miyazaki-Wilson equilibrium. We then show that this candidate equilibrium allocation is sustained by subgame perfect strategies of the market game where insurers offer participating contracts in the segments of markets (i.e. for subgroups of risk types) with cross-subsidization, and non-participating contracts in the other segments. Section 5 sketches a dynamic extension of our model. It shows that transferring underwriting profits to reserves and increasing or decreasing premiums according to the level of accumated surplus may act as a substitute to policy dividend or supplemenrary call with similar strategic effects. Such deferred premium variations involve more complex competitive mechanisms with a signalling dimension. Concluding comments follow in Section 6. Proofs are in the Appendix.

\section{The model}

We consider a large population represented by a continuum of individuals facing idiosyncratic risks of accident. All individuals are risk averse : they maximize the expected utility of wealth $u(W)$, where $W$ denotes wealth and the (twice continuously differentiable) utility function $u$ is such that $u^{\prime}>0$ and $u^{\prime \prime}<0$. If no insurance policy is taken out, we have $W=W_{N}$ in the no-accident state and $W=W_{A}$ in the accident state; $A=W_{N}-W_{A}$ is the loss from an accident ${ }^{5}$. Individuals differ according to their probability of accident $\pi$ and they have private information on their own accident probability. There are $n$ types of individuals, with $\pi=\pi_{i}$ for type $i$ with $0<\pi_{n}<\pi_{n-1}<\ldots<\pi_{1}<1$. Hence the larger the index $i$ the lower the probability of an accident. $\lambda_{i}$ is the fraction of type $i$ individuals among the whole population with $\sum_{i=1}^{n} \lambda_{i}=1$. This Section and the following focus on the two risk type case, i.e. $n=2$. Type 1 is a high risk and type 2 is a low risk and $\bar{\pi}=\lambda_{1} \pi_{1}+\left(1-\lambda_{2}\right) \pi_{2}$ denotes the average probability of loss.

Insurance contracts are offered by $m$ insurers $(m \geq 2)$ indexed by $j=1, \ldots, m$ who are the managers of the insurance firms. They may be stock insurers or mutual insurers. Stock insurers pool risks between policyholders through non-participating insurance contracts and they transfer underwriting profit to risk neutral shareholders. Mutual insurers have no shareholders : they share risks between their members only through participating contracts. The insurance corporate form is not given ex ante : it will be a consequence of the kind of insurance contracts offered at the equilibrium of the insurance market, and as we shall see this contract form (participating or nonparticipating) is the outcome of competitive pressures. The underwriting activity as well as all the other aspects of the insurance business (e.g. claims handling) are supposed to be costless. Insurers earn fixed fees in a competitive market. The mere

\footnotetext{
${ }^{5}$ The word "accident" is taken in its generic meaning: it refers to any kind of insurable loss, such as health care expenditures or fire damages.
} 
fact that they may transfer risks to risk neutral investors lead them to maximize the expected residual profit which is the difference between underwriting profits and policy dividends ${ }^{6}$.

We assume that each individual can take out only one contract. An insurance contract is written as $(k, x)$ where $k$ is the insurance premium, $x$ is the net payout in case of an accident. Hence $x+k$ is the indemnity. Participating insurance contracts also specify how policy dividends are paid or supplementary premiums are levied. For example, in the simple case where each insurer only offers a single contract, policy dividend $D$ may be written as a proportion $\gamma$ of profit per policyholder $P$ (or more generally as a function of $P$ ), with $\gamma=0$ for a non-participating contract and $\gamma=1$ for a full participating contract ${ }^{7}$. Since individual risks are independently distributed, when contract $(k, x)$ is taken out by a large population of individuals, its average profit may be written as

$$
P=\alpha_{1} P_{1}+\alpha_{2} P_{2},
$$

where $\alpha_{i}$ is the proportion of type $i$ individuals among the purchasers of this contract, with $\alpha_{1}+\alpha_{2}=1$ and $P_{1}, P_{2}$ respectively denote the expected profit made on high and low risk policyholders ${ }^{8}$. Using $D=\gamma P$ then allows us to write the expected utility of a policyholder as

$$
E u=(1-\pi) u\left(W_{N}-k+\gamma P\right)+\pi u\left(W_{A}+x+\gamma P\right),
$$

with $\pi=\pi_{1}$ or $\pi_{2}$ according to the policyholder's type.

As a reminder, let us begin with a brief presentation of the RS model. Rothschild and Stiglitz restrict attention to non-participating contracts. An equilibrium in the sense of Rothschild and Stiglitz consists of a set of contracts such that, when individuals choose contracts to maximize expected utility, $(i)$ : Each contract in the equilibrium set makes non-negative expected profit, and $(i i)$ : There is no contract outside the equilibrium set that, if offered in addition to those in the equilibrium set, would make strictly positive expected profits. This concept of equilibrium may be understood as a pure strategy subgame perfect Nash equilibrium of a game where insurers simultaneously offer contracts and individuals respond by choosing one of the contracts (or refusing them all). At equilibrium, each contract makes zero profit and

\footnotetext{
${ }^{6}$ Indeed if an insurer could increase the residual expected profit by offering other insurance policies, then he could contract with risk neutral investors and secure higher fixed fees. Note that the residual profit of a mutual is nil if profits are distributed as policy dividends or losses are absorbed through supplementary premiums. In that case, if the mutual insurer could make positive residual profit, then he would benefit from becoming a stock insurer. In the real world, the fact is the corporate form of insurance firms sometimes change and "demutualization" has been frequently observed in insurance markets. In particular, over 200 US mutual life insurance companies have demutualized since 1930 and numerous large mutuals decided to demutualize during the last decade.

${ }^{7}$ Formally, a supplementary premium is equivalent to $D<0$.

${ }^{8}$ In other words, we use the law of large number to identify the average profit with the expected profit made on a policyholder who is randomly drawn among the customers.
} 
there is no profitable deviation at the contract offering stage, given the subsequent reaction of the insurance purchasers.

Let $C_{i}^{*}=\left(k_{i}^{*}, x_{i}^{*}\right)=\left(\pi_{i} A, A-\pi_{i} A\right)$ be the actuarially fair full insurance contract for a type $i$. Rothschild and Stiglitz show that there cannot be a pooling equilibrium where both groups would buy the same contract. Only a separating equilibrium can exist : different types then choose different contracts. They establish that the only candidate separating equilibrium is such that high risk individuals (i.e. types 1 ) purchase full insurance at fair price, i.e. they choose $C_{1}^{*}$, and low risk individuals (types 2) purchase a contract $C_{2}^{* *}$ with partial coverage. $C_{2}^{* *}$ is the contract that low risk individuals most prefer in the set of (fairly priced) contracts that do not attract high risk individuals: $C_{2}^{* *}=\left(k_{2}^{* *}, x_{2}^{* *}\right)=\left(\pi_{2} A^{\prime}, A^{\prime}-\pi_{2} A^{\prime}\right)$ with $A^{\prime} \in(0, A)$ given by

$$
u\left(W_{N}-\pi_{1} A\right)=\left(1-\pi_{1}\right) u\left(W_{N}-\pi_{2} A^{\prime}\right)+\pi_{1} u\left(W_{A}+\left(1-\pi_{2}\right) A^{\prime}\right) .
$$

Rothschild and Stiglitz also show that the candidate equilibrium $C_{1}^{*}, C_{2}^{* *}$ is actually an equilibrium (in the sense of the above definition) if and only if $\lambda_{1}$ is large enough. The RS equilibrium is illustrated in Figure 1, with state-dependent wealth on each axis ${ }^{9}$. $W^{1}=W_{N}-k$ and $W^{2}=W_{A}+x$ respectively denote final wealth in the no-accident state and in the accident state. The no-insurance situation corresponds to point $E$ with coordinates $W^{1}=W_{N}$ and $W^{2}=W_{A}$. The high risk and low risk fair-odds line go through $E$, with slopes (in absolute value) respectively equal to $1-\pi_{1} / \pi_{1}$ and $1-\pi_{2} / \pi_{2}$. At $C_{1}^{*}$ the type 1 indifference curve is tangent to the type 1 fair-odds line $E F_{1}$. Similarly, $C_{2}^{*}$ is at a tangency point between a type 2 indifference curve and the type 2 fair-odds line $E F_{2} . C_{2}^{* *}$ is at the intersection between $E F_{2}$ and the type 1 indifference curve that goes through $C_{1}^{*} . E \bar{F}$ in Figure 1 corresponds to the average fair-odds line with slope $1-\bar{\pi} / \bar{\pi}$.

\section{Figure 1}

A pooling allocation with zero profit would correspond to a contract located on $E \bar{F}$, such as $C$ in Figure 2. However a pooling equilibrium cannot exist in the RS model because offering a contract like $C^{\prime}$ would be a profitable deviation that would attract low risks only.

\section{Figure 2}

When $\lambda_{1}=\lambda^{*}$, the low risk indifference curve that goes through $C_{2}^{* *}$ is tangent to $E \bar{F}$. Hence when $\lambda_{1} \geq \lambda^{*}$, as in Figure 1, the allocation $C_{1}^{*}, C_{2}^{* *}$ is a separating equilibrium of the RS model: type 1 individuals choose $C_{1}^{*}$, types 2 choose $C_{2}^{* *}$ and no insurer can make profit by offering a contract that would attract either one type or both types of individuals. Conversely when $\lambda_{1}<\lambda^{*}$, as in Figure 3, the separating allocation $C_{1}^{*}, C_{2}^{* *}$

\footnotetext{
${ }^{9}$ When no ambiguity occurs, we use the same notation for insurance contracts $(k, x)$ and their images in the $\left(W^{1}, W^{2}\right)$ plane.
} 
is Pareto-dominated by a pooling allocation like $C^{\prime}$ where all individuals choose the same contract. Hence there exists a profitable deviation in which the deviant insurer would attract all individuals and no equilibrium exists in this case.

\section{Figure 3}

The above given definition of an equilibrium assumes that each insurer can only offer one contract. At equilibrium some insurers offer $C_{1}^{*}$ and others offer $C_{2}^{* *}$. When insurers are allowed to offer a menu of contract, then the definition of an equilibrium in the sense of Rothschild and Stiglitz consists of a set of menus that break even on average, such that there is no menu of contracts outside the equilibrium set that, if offered in addition, would make strictly positive expected profits. In a game theory setting, the equilibrium is a pure strategy subgame perfect Nash equilibrium of a game where insurers simultaneously offer menus, and then individuals respond either by selecting the contract they prefer in the menus offered in the market. At equilibrium, each menu makes zero aggregate profit and there is no profitable deviation at the menu offering stage, given the subsequent reaction of the insurance purchasers. At an equilibrium, the menu $C_{1}^{*}, C_{2}^{* *}$ is offered by all insurers: types 1 choose $C_{1}^{*}$ and types 2 choose $C_{2}^{* *}$. Hence the set of equilibrium contracts is unchanged, with zero profit made on each contract. An equilibrium exists if $\lambda_{1} \geq \lambda^{* *}$ where $\lambda^{* *} \in\left(\lambda^{*}, 1\right)$. Hence the possibility of offering a menu increases the critical proportion of high risk individuals above which an equilibrium exists. It thus makes the existence of equilibrium less likely.

\section{Equilibrium with participating contracts}

We first focus on the case where each insurer offers a single contract, before considering the more general setting where insurers can offer menus.

\subsection{Case where each insurer offers one contract}

We characterize the subgame perfect equilibrium of a two stage game. At stage 1 each insurer $j$ offers a contract $C^{j}=\left(k^{j}, x^{j}\right)$ with policy dividend $D^{j}=\gamma^{j} P^{j}$, where $P^{j}$ denotes the profit per policyholder and $\gamma^{j} \in[0,1]$. The contractual offer of insurer $j$ is thus characterized by $\left(C^{j}, \gamma^{j}\right)$. At stage 2 , individuals respond by choosing the contract they prefer among the offers made by the insurers ${ }^{10}$. In other words, the only

\footnotetext{
${ }^{10}$ For any set of contracts $C=\left(C^{1}, \ldots, C^{m}\right)$ offered at stage 1 , individuals have expectations about policy dividends $D^{j}$, for all $j=1, \ldots, m$, or equivalently about the risk type distribution of individuals who choose $C^{j}$. When $C^{j}$ is actually chosen by some individuals, then these expectations coincide with equilibrium values, and otherwise there is no restriction on these expectations.
} 
difference with the RS model is that we allow insurers to offer either participating or non-participating contracts. Because this is just an extension of the RS model obtained by suppressing a restriction on the set of feasible contracts, we will call it the extended RS model.

When the population of individuals who choose $\left(C^{j}, \gamma^{j}\right)$ includes type $i$ individuals in proportion $\alpha_{i}^{j}$ with $\alpha_{1}^{j}+\alpha_{2}^{j}=1$, then we may draw the corresponding average fairodds line, labelled $E \bar{F}^{j}$ in Figure 4. It goes through $E$ and its slope is $1-\bar{\pi}^{j} / \bar{\pi}^{j}$ in absolute value, with $\bar{\pi}^{j}=\alpha_{1}^{j} \pi_{1}+\alpha_{2}^{j} \pi_{2}$. It coincides with $E F_{1}, E F_{2}$ or $E \bar{F}$ if $\alpha_{1}^{j}=1,0$ or $\lambda_{1}$. In Figure 4, point $C^{j}$ corresponds to the lottery $\left(W_{0}^{j 1}, W_{0}^{j 2}\right)$ which is associated with contract $C^{j}$ without any sharing of profit, i.e. $W_{0}^{j 1}=W_{N}-k^{j}$ and $W_{0}^{j 2}=W_{A}+x^{j 11}$. When $\gamma^{j}=1$ then contract $C^{j}$ generates a lottery on final wealth $C_{1}^{j}=\left(W_{1}^{j 1}, W_{1}^{j 2}\right)$ which is at the crossing between $E \bar{F}^{j}$ and the $45^{\circ}$ line which goes through $C^{j}$. When $0<\gamma^{j}<1$ then the lottery on final wealth associated with contract $C^{j}$ is located in the interior of the line segment $C^{j} C_{1}^{j}$, like $C_{2}^{j}$ in Figure 4.

\section{Figure 4}

As in the RS model, two types of equilibrium have to be considered in the extended RS model, either a separating equilibrium or a pooling equilibrium ${ }^{12}$. Consider first a separating equilibrium : types 1 and types 2 would then choose different contracts. We know from the RS model that if a separating equilibrium exists, then the corresponding lotteries on final wealth should be $C_{1}^{*}$ for type 1 and $C_{2}^{* *}$ for type 2 , for otherwise a profitable deviation would exist. We also know from the RS model that there does not exist any profitable deviation through non-participating contracts if and only if $\lambda_{1} \geq \lambda^{*}$. Since any deviation through a participating contract can be replicated by a deviation through a non-participating contract ${ }^{13}$, we deduce that $\lambda_{1} \geq \lambda^{*}$ is a necessary and sufficient condition for a separating equilibrium to exist.

Consider now a pooling equilibrium: type 1 and type 2 individuals then choose the same contract. As in the RS model, the equilibrium lottery on final wealth is necessarily located on $E \bar{F}$, More specifically, this lottery has to be located at the

\footnotetext{
${ }^{11}$ Of course the lottery depends on the policyholder's type: $W^{1}=W_{0}^{j 1}$ (resp. $W_{0}^{j 2}$ ) with probability $\pi_{i}$ (resp. $1-\pi_{i}$ ) for a type $i$ individual.

${ }^{12}$ We can check that individuals do not randomize at equilibrium. In particular there is no semiseparating equilibrium where two different contracts would be offered and all $\ell$-types (resp. $h$-types) would choose the same contract while $h$-types (resp. $\ell$-types) would be shared between both contracts.

${ }^{13}$ Replicating a deviation means that there exists a non-participating contract that would induce an amount of profit for the deviant which is equal to the residual profit (i.e. profit after policy dividends have been paid) obtained with participating contract offered in deviation from equilibrium. Indeed assume for instance that insurer $j$ deviates from its equilibrium strategy to the participating contract $C^{j}=\left(k^{j}, x^{j}\right)$, with a proportion of profit $\gamma^{j}$ distributed as policy dividends. Let $P^{j}$ be the profit of insurer $j$ at a continuation equilibrium following this deviation to $C^{j}$ and consider the non-participating contract $C^{j \prime}=\left(k^{j}-\gamma^{j} P^{j}, x^{j}+\gamma^{j} P^{j}\right)$. At a continuation equilibrium following the deviation to $C^{j^{\prime}}$, the profit of insurer $j$ would be equal to its residual profit after the deviation to $C^{j}$.
} 
tangency point between $E \bar{F}$ and a type 2 indifference curve: this is $\widehat{C}$ in Figure 5 . Indeed, at any other point on $E \bar{F}$ it would be possible to make profit by deviating to a non-participating contract that would attract types 1 (and also possibly types 2 ), which would contradict the definition of an equilibrium. We also know from the RS model (see Figure 2) that a non-participating contract cannot be offered at such a pooling equilibrium, for otherwise there would exist a profitable deviation attracting types 2, while types 1 would keep choosing the same contract. Let us focus on a symmetric pooling equilibrium with a participating contract offered by each insurer and such that $\gamma^{1}=\gamma^{2}=\ldots=\gamma^{m}=\gamma$.

\section{Figure 5}

W.l.o.g. consider a deviation where an insurer offers a non-participating contract $C^{\prime}$, while other insurers keep offering $\widehat{C}^{14}$. $\widehat{C}$ is a pooling equilibrium if for any deviation $C^{\prime}$ there exists a continuation equilibrium which makes it unprofitable. We may restrict attention to deviations such that types 2 choose $C^{\prime}$ and types 1 keep choosing $\widehat{C}^{15}$. As illustrated in Figure 5 , contract $\widehat{C}$ will then generate a lottery $\widehat{C}_{1}$ if $\gamma=1$ and a lottery like $\widehat{C}_{2}$ on the $\widehat{C} \widehat{C}_{2}$ line segment if $0<\gamma<1$. If $C^{\prime}$ in the grey area in Figure 5 , then any continuation equilibrium is such that types 2 choose $C^{\prime}$, types 1 choose $\widehat{C}$, and the deviant insurer makes positive profit. For $\lambda_{1}$ and $\lambda_{2}$ given (and thus for $\widehat{C}$ given), this grey area is shrinking when $\gamma$ is increasing. When looking for the existence of a pooling equilibrium we may thus restrict attention to the case where $\gamma=1$ since it corresponds to the smallest set of profitable deviations ${ }^{16}$. Observe that the type 2 expected utility is lower at any lottery in the grey area than at $C_{2}^{* *}$. Thus $\lambda_{1} \leq \lambda^{*}$ is a sufficient condition for the grey area to vanish. In that case (which is represented in Figure 6) there does not exists any deviation $C^{\prime}$ with positive profit at all continuation equilibrium and thus a pooling equilibrium exists. In the case drawn in Figure 5 deviations located in the grey area are profitable at any continuation equilibrium and there is no pooling equilibrium. We may observe that a pooling equilibrium at $\widehat{C}$ coexists with a separating equilibrium at $C_{1}^{*}, C_{2}^{* *}$ when $\lambda_{1}$ is larger but close to $\lambda^{*}$.

\section{Figure 6}

Proposition 1 An equilibrium always exists in the extended $R S$ model with a single contract per insurer. A participating contract is offered at a pooling equilibrium, while

\footnotetext{
${ }^{14}$ Once again any deviation through a participating contract could be replicated by a deviation through a non-participating contract.

${ }^{15}$ Obviously, deviation $C^{\prime}$ that would attract only type 1 individuals cannot be profitable. If $C^{\prime}$ attract both types, then there exist out of equilibrium expectations on policy dividends for $\widehat{C}$ (or on the risk type of individuals who choose $\widehat{C}$ ) such that $C^{\prime}$ canot be profitable at such a continuation equilibrium : for instance expectations stipulating that $\widehat{C}$ is chosen by type 2 individuals only.

${ }^{16}$ Note that when $\gamma=1$ the equilibrium contract (i.e. the lottery without any sharing of profit) could be located at any point on the $45^{\circ}$ line that goes through $\widehat{C}$.
} 
contracts may be participating or non-participating at a separating equilibrium. A separating equilibrium exists when $\lambda_{1} \geq \lambda^{*}$ with the same pair of contracts $C_{1}^{*}, C_{2}^{* *}$ and the same individual choices as in the $R S$ model. There exists a pooling equilibrium where all individuals choose $\widehat{C}$ when $\lambda_{1} \leq \lambda^{*}$. When $\lambda_{1}$ is larger than $\lambda^{*}$ but close to $\lambda^{*}$, a pooling equilibrium at $\widehat{C}$ coexists with a separating equilibrium at $C_{1}^{*}, C_{2}^{* *}$.

Proposition 1 states that an equilibrium always exists in the extended RS model with a single contract per insurer. It coincides with the Rothschild-Stiglitz separating allocation when the proportion of high risks is large and it is a pooling allocation when this proportion is low, with an overlap of the two regimes. The pooling allocation maximizes the type 2 expected utility among the allocations that break even on aggregate and it should be sustained by a participating contract, contrary to the separating allocation that may be sustained by participating or non-participating contracts.

\subsection{Case where insurers offer menus of contracts}

Let us assume now that each insurer $j$ offers a menu of contracts $C_{1}^{j}, C_{2}^{j}$ where $C_{i}^{j}$ is chosen by type $i$ individuals. Each contract in the menu may be participating or nonparticipating. If both contracts are participating, then the contractual arrangements specify how distributed profits are splitted between the policyholders ${ }^{17}$. Because of the information asymmetry between insurers and insureds the lotteries on final wealth should satisfy incentives constraints, i.e. type 1 individuals should weakly prefer the lottery generated by $C_{1}^{j}$ to the lottery generated by $C_{2}^{j}$ and conversely for type 2 .

The lotteries generated at a candidate equilibrium of the extended RS model with menus should maximize the expected utility of type 2 individuals in the set of lotteries that break even and that satisfy incentive compatibility constraints ${ }^{18}$. We may refer to these lotteries as the Miyazaki-Spence-Wilson (MSW) allocation because they correspond to the equilibrium contracts under the anticipatory equilibrium hypothesis introduced by Wilson (1977) and Miyazaki (1977) and further developped by Spence (1978). We know from Crocker and Snow (1986) that there exist a threshold $\lambda^{* *}$ in $\left(\lambda^{*}, 1\right)$ such that the MSW allocation coincide with the Rothschild-Stiglitz

\footnotetext{
${ }^{17}$ For instance, policy dividends paid to the individuals who have chosen $C_{1}^{j}$ may depend on the profit made on $C_{1}^{j}$ only, or on the aggregate profit on $\left(C_{1}^{j}, C_{2}^{j}\right)$.

${ }^{18}$ Obviously the menu offered by insurers should break even, for otherwise insurers would deviate to a "zero contract" without indemnity and premium, i.e. they would exit the market. The equilibrium menu could neither make positive profit because in such a case there would exist a profitable deviation in which an insurer would attract all insureds by slightly decreasing the premiums of both contracts. If the menu offered at equilibrium were not second-best Pareto-optimal then each insurer could deviate to a profitable incentive-compatible menu of non-participating contracts that would attract both types, hence a contradiction with the definition of an equilibrium. If the expected utility of type 2 individuals were not maximized in this set of second-best Pareto-optimal allocation then it would be possible to attract individuals from the type 2 group by offering a menu of non-participating contracts that would be profitable even if it also attracts type 1 individuals, hence once again a contradiction with the definition of an equilibrium.
} 
pair of contracts $C_{1}^{*}, C_{2}^{* *}$ without cross-subsidization when $\lambda_{1} \geq \lambda^{* *}$, while it involves cross-subsidization between contracts when $\lambda_{1} \leq \lambda^{* * 19}$. We also know that the set of second-best Pareto-optimal lotteries is represented in the $W^{1}, W^{2}$ plane by a locus, denoted $G H$ in Figures 7 and 8 . Figure 7 corresponds to the case where $\lambda_{1} \geq \lambda^{* *}$. In that case, there exists an equilibrium in the RS model, and it is obviously still the case in the extended RS model: the equilibrium coincides with the Rothschild-Stiglitz allocation, with full coverage at $C_{1}^{*}$ for type 1 and partial coverage at $C_{2}^{* *}$ for type $2^{20}$.

\section{Figure 7}

The case where $\lambda_{1}<\lambda^{* *}$ is drawn in Figure 8. The type 2 expected utility is maximized in the set of second-best allocations at $\widetilde{C}_{2}$. The lottery $\widetilde{C}_{1}$ should then be attributed to type 1 individuals. $\widetilde{C}_{1}$ is a full coverage policy chosen by type 1 individuals. It is cross-subsidized by $\widetilde{C}_{2}$, which is a partial coverage policy chosen by types 2. $\widetilde{C}_{1}, \widetilde{C}_{2}$ is thus the candidate equilibrium lottery. Assume that $\widetilde{C}_{2}$ is a non-participating contract and $\widetilde{C}_{1}$ is a participating contract with full distribution of the profits or repayment of the losses made by the insurer. Any menu of contracts offered by a deviant insurer can be profitable only if it includes a contract $C^{\prime}$ which only attracts individuals from the type 2 group and we may assume w.l.o.g. that $C^{\prime}$ is a non-participating contract. When such an offer is made, the type 1 lottery shifts from $\widetilde{C}_{1}$ to $C_{1}^{*}$ since type 1 individuals are now the only customers of the nondeviant insurers and $\widetilde{C}_{1}$ is a participating contract with full repayment of losses by policyholders. If $C^{\prime}$ is profitable when chosen by types 2 and not attractive for types 1 , then type 2 individuals reach an expected utility which is (weakly) lower than at $C_{2}^{* *}$, and thus lower than at $\widetilde{C}_{2}$ when $\lambda_{1}<\lambda^{* *}$. Hence, following such a deviation where $C^{\prime}$ is offered, there exists a continuation equilibrium where type 2 individuals keep choosing $\widetilde{C}_{2}$ and the deviant insurer doesn't make any profit. We conclude that $\widetilde{C}_{1}, \widetilde{C}_{2}$ is a separating equilibrium with cross-subsidization between contracts when $\lambda_{1}<\lambda^{* *}$.

\section{Figure 8}

Proposition 2 An equilibrium always exists in the extended $R S$ model with menus; it is generically unique and it coincides with the $M S W$ allocation. When $\lambda_{1} \geq \lambda^{* *}$, the separating contracts of the $R S$ model $C_{1}^{*}, C_{2}^{* *}$ are offered at equilibrium without crosssubsidization and they may be participating or non-participating. When $\lambda_{1} \leq \lambda^{* *}$, the separating contracts $\widetilde{C}_{1}, \widetilde{C}_{2}$ are offered at equilibrium with cross-subsidization. Contract $\widetilde{C}_{1}$ which is chosen by type 1 individuals is participating, while $\widetilde{C}_{2}$ which is chosen by type 2 individuals may be participating or non-participating. The menu of contracts offered at an equilibrium with cross-subsidization maximizes the type 2 expected utility under the zero-profit constraint and incentive compatibility conditions.

\footnotetext{
${ }^{19}$ The MSW equilibrium is unique (in the two risk type case) except when $\lambda_{1}=\lambda_{1}^{* *}$.

${ }^{20}$ Participating contracts are thus useless when $\lambda_{1} \geq \lambda^{* *}$.
} 
Proposition 2 states that a unique equilibrium exists in the extended RS model with menus offered by insurers. It coincides with the MSW allocation, which entails crosssubsidization and a participating contract offered to high risks when $\lambda_{1} \leq \lambda^{* *}$, while there is no cross-subsidization and participating contracts are useless when $\lambda \geq \lambda^{* *}$.

\section{The $n$-type problem}

We now assume that there is an arbitrary number of risk types in the population. More heavy notations are required to precisely describe the market game. As before, each insurer offers a menu of participating or non-participating contracts at the first stage and individuals respond by choosing their prefered policy at the second stage. A strategy of insurer $j$ is defined by a menu of $n$ contracts, one for each type of individual, written as $C^{j}=\left(C_{1}^{j}, C_{2}^{j}, \ldots, C_{n}^{j}, D^{j}().\right)$ where $C_{h}^{j}=\left(k_{h}^{j}, x_{h}^{j}\right)$ specifies the premium $k_{h}^{j}$ and the net indemnity $x_{h}^{j}$. $D^{j}($.$) is a policy dividend strategy, i.e. a way to distribute the net$ profits made on $C^{j}$, with $D^{j}()=.\left(D_{1}^{j}(),. \ldots, D_{n}^{j}().\right)$, where $D_{h}^{j}\left(N_{1}^{j}, P_{1}^{j}, \ldots, N_{n}^{j}, P_{n}^{j}\right)$ denotes the policy dividend paid to each individual who has chosen contract $C_{h}^{j}$ when $N_{i}^{j}$ individuals (expressed as a proportion of the whole population) have chosen contract $C_{i}^{j}$ with average profit per policyholder $P_{i}^{j}$, with $i=1, \ldots, n$ and $\sum_{j=1}^{m} \sum_{i=1}^{n} N_{i}^{j}=1^{21} . C^{j}$ is fully participating if

$$
\sum_{h=1}^{n} N_{h}^{j} D_{h}^{j}\left(N_{1}^{j}, P_{1}^{j}, \ldots, N_{n}^{j}, P_{n}^{j}\right) \equiv \sum_{h=1}^{n} N_{h}^{j} P_{h}^{j}
$$

while $D_{h}^{j}\left(N_{1}^{j}, P_{1}^{j}, \ldots, N_{n}^{j}, P_{n}^{j}\right) \equiv 0$ for all $h$ when $C^{j}$ is non-participating 22 . Let $C \equiv$ $\left(C^{1}, C^{2}, \ldots, C^{m}\right)$ be the profile of contract menus offered in the market. The strategy of a type $i$ individual specifies for all $j$ and all $h$ the probability $\sigma_{i h}^{j}(C)$ to choose $C_{h}^{j}$ as a function of $C$. The contract choice strategy of type $i$ individual is thus defined by $\sigma_{i}(C) \equiv\left\{\sigma_{i h}^{j}(C) \in[0,1]\right.$ for $j=1, \ldots, m$ and $h=1, \ldots, n$ with $\left.\sum_{j=1}^{m} \sum_{h=1}^{n} \sigma_{i h}^{j}(C)=1\right\}$ for all $C$. Let $\sigma(.) \equiv\left(\sigma_{1}(),. \sigma_{2}(),. \ldots, \sigma_{n}().\right)$ be a profile of individuals' strategies.

When an insurance contract $C_{h}^{j}=\left(k_{h}^{j}, x_{h}^{j}\right)$ is taken out by a type $i$ individual, with (non-random) policy dividend $D_{h}^{j}$, the policyholder's expected utility and the

\footnotetext{
${ }^{21}$ Once again $D_{h}^{j}<0$ corresponds to a supplementary premium levied on $C_{h}^{j}$. We assume that $D_{h}^{j}$ is defined when $\sum_{i=1}^{n} N_{i}^{j}>0$ and it does not depend on $P_{i}^{j}$ when $N_{i}^{j}=0$ since $P_{i}^{j}$ is not defined in that case.

${ }^{22} C^{j}$ may be fully participating with $D_{h}^{j} \equiv 0$ for some $h$. In other words, a fully participating menu may include non-participating policies.
} 
corresponding insurer's profit are respectively written as

$$
\begin{aligned}
& U_{i}\left(C_{h}^{j}, D_{h}^{j}\right) \equiv\left(1-\pi_{i}\right) u\left(W_{N}-k_{h}^{j}+D_{h}^{j}\right)+\pi_{i} u\left(W_{A}+x_{h}^{j}+D_{h}^{j}\right), \\
& \Pi_{i}\left(C_{h}^{j}\right) \equiv\left(1-\pi_{i}\right) k_{h}^{j}-\pi_{i} x_{h}^{j} .
\end{aligned}
$$

Definition 1 A profile of strategies $\widetilde{\sigma}(),. \widetilde{C} \equiv\left(\widetilde{C}^{1}, \widetilde{C}^{2}, \ldots, \widetilde{C}^{m}\right)$, where $\widetilde{C}^{j}=\left(\widetilde{C}_{1}^{j}, \widetilde{C}_{2}^{j}, \ldots, \widetilde{C}_{n}^{j}, \widetilde{D}^{j}().\right)$, is a subgame perfect Nash equilibrium of the market game if:

$$
\begin{aligned}
& \sum_{j=1}^{m} \sum_{h=1}^{n} \widetilde{\sigma}_{i h}^{j}(C) U_{i}\left(C_{h}^{j}, \bar{D}_{h}^{j}(C)\right)=\max \left\{U_{i}\left(C_{h}^{j}, \bar{D}_{h}^{j}(C)\right) ; j=1, \ldots, m, h=1, \ldots, n\right\} \\
& \quad \text { for all } i=1, \ldots, n \text { and all } C \\
& \qquad \bar{\Pi}^{j}(\widetilde{C}) \geq \bar{\Pi}^{j}\left(C^{j}, \widetilde{C}^{-j}\right) \text { for all } C^{j} \text { and all } j=1, \ldots, m
\end{aligned}
$$

where $C \equiv\left(C^{1}, C^{2}, \ldots, C^{m}\right), C^{j}=\left(C_{1}^{j}, C_{2}^{j}, \ldots, C_{n}^{j}, D^{j}().\right), \widetilde{C}^{-j}=\left(\widetilde{C}^{1}, \ldots, \widetilde{C}^{j-1}, \widetilde{C}^{j+1}, \ldots\right.$, $\left.\widetilde{C}^{m}\right)$ and

$$
\begin{gathered}
\bar{\Pi}^{j}(C) \equiv \sum_{h=1}^{n} \sum_{i=1}^{n} \lambda_{i} \widetilde{\sigma}_{i h}^{j}(C)\left[\Pi_{i}\left(C_{h}^{j}\right)-\bar{D}_{h}^{j}(C)\right], \\
\bar{D}_{h}^{j}(C) \equiv D_{h}^{j}\left(\bar{N}_{1}^{j}(C), \bar{P}_{1}^{j}(C), \ldots, \bar{N}_{n}^{j}(C), \bar{P}_{n}^{j}(C)\right) \text { if } \sum_{i=1}^{n} \bar{N}_{i}^{j}(C)>0, \\
\bar{N}_{h}^{j}(C)=\sum_{i=1}^{n} \lambda_{i} \widetilde{\sigma}_{i h}^{j}(C) \text { and } \bar{P}_{h}^{j}(C)=\frac{\sum_{i=1}^{n} \lambda_{i} \widetilde{\sigma}_{i h}^{j}(C) \Pi_{i}\left(C_{h}^{j}\right)}{\sum_{i=1}^{n} \lambda_{i} \widetilde{\sigma}_{i h}^{j}(C)} \text { if } \bar{N}_{h}^{j}(C)>0 .
\end{gathered}
$$

The notations in Definition 1 are as follows. Consider a profile of contracts $C=$ $\left(C^{1}, \ldots, C^{m}\right)$ where $C^{j}=\left(C_{1}^{j}, C_{2}^{j}, \ldots, C_{n}^{j}, D^{j}().\right)$ is the menu offered by insurer $j . \bar{N}_{h}^{j}(C)$ is the proportion of individuals who choose $C_{h}^{j}$ when $C$ is offered, with $\bar{P}_{h}^{j}(C)$ the profit per policyholder. Then $\bar{D}_{h}^{j}(C)$ and $\bar{\Pi}^{j}(C)$ defined by (4) and (5) respectively denote the policy dividend for contract $C_{h}^{j}$ and the residual profit of insurer $j$. They depend on the set of contracts $C$ offered in the market and on the profile of individuals'contract choice strategy $\widetilde{\sigma}($.$) . In particular \bar{D}_{h}^{j}(C)=\widetilde{D}_{h}^{j}\left(N_{1}^{j}(C), P_{1}^{j}(C), \ldots, N_{n}^{j}(C), P_{n}^{j}(C)\right)$ if $C^{j}=\widetilde{C}^{j}$.

Keeping these notations in mind, (2) and (3) correspond to the standard definition of a subgame perfect Nash equilibrium. From (2), choosing $C_{h}^{j}$ with probability $\widetilde{\sigma}_{i h}^{j}(C)$ is an optimal contract choice for type $i$ individuals. (3) means that $\widetilde{C}^{j}$ is an optimal 
offer by insurer $j$ (i.e. an offer that maximizes residual profit) when $\widetilde{C}^{-j}$ is offered by the other insurers, given the contract choice strategy of individuals.

Let $C^{*}$ denote the menu of contracts at a symmetric equilibrium of the market game (defined as an equilibrium where all insurers offer the same menu and individuals are evenly shared between insurers), with $\widetilde{C}^{1}=\widetilde{C}^{2}=\ldots=\widetilde{C}^{m}=$ $C^{*}=\left(C_{1}^{*}, C_{2}^{*}, \ldots, C_{n}^{*}, D^{*}().\right)$ and $C_{h}^{*}=\left(k_{h}^{*}, x_{h}^{*}\right)$ for all $h=1, \ldots, n$ and $D^{*}(.) \equiv$ $\left(D_{1}^{*}(),. \ldots, D_{n}^{*}().\right)$. If individuals do not randomize between contracts (i.e. all individuals of a given type choose the same contract), $C_{i}^{*}=\left(k_{i}^{*}, x_{i}^{*}\right)$ denotes the contract chosen by type $i$ individuals.

A symmetric equilibrium of the market game sustains an equilibrium allocation $\left\{\left(W_{i}^{1 *}, W_{i}^{2 *}\right), i=1, \ldots, n\right\}$, where $\left(W_{i}^{1 *}, W_{i}^{2 *}\right)$ is the lottery on final wealth induced by the equilibrium strategies for type $i$ individuals (meaning that their final wealth is $W_{i}^{1 *}$ with probability $1-\pi_{i}$ and $W_{i}^{2 *}$ with probability $\left.\pi_{i}\right)$ with

$$
\begin{aligned}
& W_{i}^{1 *}=W_{N}-k_{i}^{*}+D_{i}^{*}, \\
& W_{i}^{2 *}=W_{A}+x_{i}^{*}+D_{i}^{*},
\end{aligned}
$$

where

$$
D_{i}^{*} \equiv D_{i}^{*}\left(\lambda_{1} / m, \Pi_{1}^{*}, \ldots, \lambda_{n} / m, \Pi_{n}^{*}\right) \text { with } \Pi_{i}^{*} \equiv \Pi_{i}\left(C_{i}^{*}\right) .
$$

To establish the existence of such a symmetric equilibrium, we first characterize a candidate equilibrium allocation by following the Spence (1978) approach to the MiyazakiWilson equilibrium with an arbitrary number of types, and next we show that this allocation is sustained by strategy profiles which are a subgame perfect Nash equilibrium of the market game.

As Spence (1978), let us first define a sequence of expected utility levels $\bar{u}_{i}$ as follows:

$$
\begin{aligned}
& \bar{u}_{1}=\max \left(1-\pi_{1}\right) u\left(W^{1}\right)+\pi_{1} u\left(W^{2}\right) \\
& \text { with respect to } W^{1}, W^{2}, \text { subject to } \\
& \left(1-\pi_{1}\right) W^{1}+\pi_{1}\left(W^{2}+A\right)=W_{N}
\end{aligned}
$$

and for $2 \leq k \leq n, \bar{u}_{i}$ is defined as

$$
\begin{aligned}
& \bar{u}_{i}=\max \left(1-\pi_{i}\right) u\left(W_{i}^{1}\right)+\pi_{i} u\left(W_{i}^{2}\right) \\
& \text { with respect to } W_{h}^{1}, W_{h}^{2}, h=1, \ldots, i, \text { subject to } \\
& \left(1-\pi_{h}\right) u\left(W_{h}^{1}\right)+\pi_{h} u\left(W_{h}^{2}\right) \geq \bar{u}_{h} \text { for } h<i, \\
& \left(1-\pi_{h}\right) u\left(W_{h}^{1}\right)+\pi_{h} u\left(W_{h}^{2}\right) \geq\left(1-\pi_{h}\right) u\left(W_{h+1}^{1}\right)+\pi_{h} u\left(W_{h+1}^{2}\right) \text { for } h<i, \\
& \sum_{h=1}^{i}\left[\left(1-\pi_{h}\right) W_{h}^{1}+\pi_{h}\left(W_{h}^{2}+A\right)\right]=W_{N} .
\end{aligned}
$$


Let $\mathbb{P}_{i}$ denote the problem which defines $\bar{u}_{i}$, with $i=1, \ldots, n$. The objective function in $\mathbb{P}_{i}$ is the expected utility of type $i$ individuals by restricting attention to individuals with types 1 to $i$. Constraints (6) ensure that higher risk individuals (i.e. $h<i$ ) get expected utility no less than $\bar{u}_{h}$. (7) are incentive compatibility constraints : since we maximize the expected utility of type $i$ individuals, the only constraints that may be binding are those that keep type $h$ individuals (with $h<i$ ) from choosing the policy targeted for type $h+1$. (8) is the break-even constraint. For $n=2$, the optimal solution to $\mathbb{P}_{2}$ is the Miyazaki-Wilson equilibrium allocation considered in Section 3. Let $\left\{\left(\widehat{W}_{i}^{1}, \widehat{W}_{i}^{2}\right), i=1, \ldots, n\right\}$ be the optimal solution to $\mathbb{P}_{n}$. The following Lemmas are adapted from Spence (1978).

Lemma 1 There exists $\ell_{\theta} \in\{0, \ldots, n\}, \theta=0, \ldots, \bar{\theta}+1$ with $\ell_{0}=0<\ell_{1} \leq \ell_{2} \ldots \leq \ell_{\bar{\theta}}$ $<\ell_{\bar{\theta}+1}=n$ such that for all $\theta=0, \ldots, \bar{\theta}$

$$
\begin{aligned}
& \sum_{i=\ell_{\theta}+1}^{h} \lambda_{i}\left[W_{N}-\left(1-\pi_{i}\right) \widehat{W}_{i}^{1}-\pi_{i}\left(\widehat{W}_{i}^{2}+A\right)\right]<0 \text { for all } h=\ell_{\theta}+1, \ldots, \ell_{\theta+1}-1, \\
& \sum_{i=\ell_{\theta}+1}^{\ell_{\theta+1}} \lambda_{i}\left[W_{N}-\left(1-\pi_{i}\right) \widehat{W}_{i}^{1}-\pi_{i}\left(\widehat{W}_{i}^{2}+A\right)\right]=0 .
\end{aligned}
$$

Furthermore, we have

$$
\begin{aligned}
& \left(1-\pi_{i}\right) u\left(\widehat{W}_{i}^{1}\right)+\pi_{i} u\left(\widehat{W}_{i}^{2}\right)=\bar{u}_{i} \text { if } i \in\left\{\ell_{1}, \ell_{2}, \ldots, n\right\} \\
& \left(1-\pi_{i}\right) u\left(\widehat{W}_{i}^{1}\right)+\pi_{i} u\left(\widehat{W}_{i}^{2}\right)>\bar{u}_{i} \text { otherwise. }
\end{aligned}
$$

Lemma 2 There does not exist any incentive compatible allocation $\left\{\left(W_{h}^{1}, W_{h}^{2}\right), h=\right.$ $1, \ldots, n\}$ such that

$$
\left(1-\pi_{\ell_{\theta}}\right) u\left(W_{\ell_{\theta}}^{1}\right)+\pi_{\ell_{\theta}} u\left(W_{\ell_{\theta}}^{2}\right) \geq \bar{u}_{\ell_{\theta}} \text { for all } \theta=1, \ldots, \bar{\theta}+1
$$

and

$$
\sum_{h=1}^{n} \lambda_{h}\left[W_{N}-\left(1-\pi_{h}\right) W_{h}^{1}-\pi_{h}\left(W_{h}^{2}+A\right)\right]>0 .
$$

The sequence $\bar{u}_{i}, i=1, \ldots, n$ corresponds to reservation utilities. If type $i$ 's expected utility were lower than $\bar{u}_{i}$, then it would be possible to make positive profit by attracting type $i$ individuals and all more risky types $h<i$. Maximizing type $i$ expected utility in $\mathbb{P}_{i}$ may require to increase the expected utility of more risky types over their reservation utility $\bar{u}_{h}$, in order to relax their incentive compatibility constraints. The optimal solution to $\mathbb{P}_{i}$ involves a trade off between reducing the cost of more risky types and relaxing their incentive compatibility constraints. This trade off may tip in 
favor of the reduction of cost or of the relaxation of incentive compatibility constraints. Constraint (6) is binding in the first case and it is slack in the second one. Lemma 1 characterizes the optimal solution to this trade off in $\mathbb{P}_{n}$. The Lemma states that risk types are pooled in subgroups indexed by $\theta$. Within each subgroup, all types except the highest (i.e. $h=\ell_{\theta}+1, \ldots, \ell_{\theta+1}-1$ ) get more than their reservation utility $\bar{u}_{h}$, with negative profit over this subset of individuals. They are cross-subsidized by the highest risk type, i.e. by $\ell_{\theta+1}$ ). Type $\ell_{\theta+1}$ just reach its reservation utility $\bar{u}_{\ell_{\theta+1}}$ with zero profit over the whole subgroup. Increasing the expected utility of type $\ell_{\theta+1}$ over $\bar{u}_{\ell_{\theta+1}}$ would be suboptimal. Lemma 1 is illustrated in Figure 9, with $n=5, \bar{\theta}=2, \ell_{1}=3$ and $\ell_{2}=4$. There are three subgroups in this example: type $i=3$ cross-subsidizes types 1 and 2, while the contracts offered to types 4 and 5 make zero profit. We have $u_{h}>\bar{u}_{h}$ for $h=1,2$ and $u_{h}=\bar{u}_{h}$ for $h=3,4$ and 5 , where $u_{h}$ is the type $h$ expected utility at the optimal solution to $\mathbb{P}_{n}$.

\section{Figure 9}

Lemma 2 states that no insurer can make positive profit by attracting all individuals and offering more than $\bar{u}_{\ell_{\theta}}$ to threshold types $\ell_{\theta}$. Indeed suppose that there exists an allocation close to $\left\{\left(\widehat{W}_{h}^{1}, \widehat{W}_{h}^{2}\right), h=1, \ldots, n\right\}$ that provides more than $\bar{u}_{\ell_{\theta}}$ to types $\ell_{\theta}$ and that make positive profit over subgroup $h=\ell_{\theta}+1, \ldots, \ell_{\theta+1}$. Such an allocation would provide an expected utility larger than $\bar{u}_{h}$ for all $h=\ell_{\theta}+1, \ldots, \ell_{\theta+1}-1$ (this is just a consequence of the second part of Lemma 1), which would contradict the definition of $\bar{u}_{\ell_{\theta}+1}$. The proof of Lemma 2 - which follows Spence (1978) - shows that this argument extends to allocations that are not close to $\left\{\left(\widehat{W}_{h}^{1}, \widehat{W}_{h}^{2}\right), h=1, \ldots, n\right\}$. The main consequence of Lemma 2 is that it is impossible to make positive profit in a deviation from $\left\{\left(\widehat{W}_{h}^{1}, \widehat{W}_{h}^{2}\right), h=1, \ldots, n\right\}$ if threshold types are guaranteed to get at least $\bar{u}_{\ell_{\theta}+1}$.

Lemmas 1 and 2 easily extend to allocations where individuals of a given type may randomize between contracts that are equivalent for him. An allocation is then a typedependent randomization over a set of lotteries. Formally, an allocation is defined by a set of lotteries $\left\{\left(W_{s}^{1}, W_{s}^{2}\right), s=1, \ldots, N\right\}$ and individuals choices $\sigma \equiv\left(\sigma_{1}, \sigma_{2}, \ldots, \sigma_{n}\right)$ with $\sigma_{i}=\left(\sigma_{i 1}, \ldots, \sigma_{i N}\right)$, where $\sigma_{i s}$ is the probability that a type $i$ individual chooses $\left(W_{s}^{1}, W_{s}^{2}\right)$, with $\sum_{\ell=1}^{N} \sigma_{i s}=1$. In other words, type $i$ individuals get a compound lottery $\widetilde{W}_{i}$ generated by their mixed strategy $\sigma_{i}$ over available lotteries $\left\{\left(W_{s}^{1}, W_{s}^{2}\right), s=\right.$ $1, \ldots, N\}^{23}$. An allocation is incentive compatible if

$$
\sum_{s=1}^{N} \sigma_{i s}\left[\left(1-\pi_{i}\right) u\left(W_{s}^{1}\right)+\pi_{i} u\left(W_{s}^{2}\right)\right]=\max \left\{\left(1-\pi_{i}\right) u\left(W_{s}^{1}\right)+\pi_{i} u\left(W_{s}^{2}\right), s=1, \ldots, N\right\},
$$

\footnotetext{
${ }^{23} N$ is given but arbitrarily large.
} 
for all $i=1, \ldots, n-1$. In words, an allocation is incentive compatible when individuals only choose their best contract with positive probability. The definition of Problem $\mathbb{P}_{h}$ for $h=1, \ldots, n$ can be extended straightforwardly to this more general setting, with unchanged definition of $\bar{u}_{h}$. In particular, individuals choose only one (non compound) lottery at the optimal solution to $\mathbb{P}_{h}$, and the optimal solution of $\mathbb{P}_{n}$ is still $\widetilde{W}_{i}=\widehat{W}_{i}{ }^{24}$. Lemma 1 is thus still valid. Lemma 3 straighforwardly extends Lemma 2 to the case where individuals may randomize between contract.

Lemma 3 There does not exist any incentive compatible allocation with randomization $\left\{\left(W_{s}^{1}, W_{s}^{2}\right), s=1, \ldots, N ; \sigma \equiv\left(\sigma_{1}, \sigma_{2}, \ldots, \sigma_{n}\right)\right\}$ such that

$$
\sum_{s=1}^{N} \sigma_{\ell_{\theta}, s}\left[\left(1-\pi_{\ell_{\theta}}\right) u\left(W_{s}^{1}\right)+\pi_{\ell_{\theta}} u\left(W_{s}^{2}\right)\right] \geq \bar{u}_{\ell_{\theta}} \text { for all } \theta=1, \ldots, \bar{\theta}+1
$$

and

$$
\sum_{h=1}^{n} \lambda_{h}\left\{\sum_{s=1}^{N} \sigma_{h s}\left[W_{N}-\left(1-\pi_{h}\right) W_{s}^{1}-\pi_{h}\left(W_{s}^{2}+A\right)\right]\right\}>0 .
$$

Proposition $3\left\{\left(\widehat{W}_{i}^{1}, \widehat{W}_{i}^{2}\right), i=1, \ldots, n\right\}$ is an equilibrium allocation sustained by a symmetric equilibrium of the market game where insurers offer participating contracts. Type $i$ individuals choose $C_{i}^{*}=\widehat{C}_{i} \equiv\left(\widehat{k}_{i}, \widehat{x}_{i}\right)$ with $\widehat{k}_{i}=W_{N}-\widehat{W}_{i}^{1}, \widehat{x}_{i}=\widehat{W}_{i}^{2}-W_{A}$ and $D^{*}($.$) is such that$

$$
\begin{aligned}
& \sum_{i=1}^{n} D_{i}^{*}\left(N_{1}, P_{1}, \ldots, N_{n}, P_{n}\right) \equiv \sum_{i=1}^{n} N_{i} P_{i} \\
& D_{i}^{*}\left(\frac{\lambda_{1}}{m}, \Pi\left(\widehat{C}_{1}\right), \ldots, \frac{\lambda_{n}}{m}, \Pi\left(\widehat{C}_{n}\right)\right)=0 \text { for all } i=1, \ldots, n \\
& D_{\ell_{\theta}}^{*}\left(N_{1}, P_{1}, \ldots, N_{n}, P_{n}\right) \equiv 0 \text { for all } \theta=1, \ldots, \bar{\theta}+1 .
\end{aligned}
$$

Proposition 3 establishes the existence of a symmetric equilibrium in the extended RS model with an arbitrary number of types. Each insurer offers $C^{*}=\left(\widehat{C}_{1}, \ldots, \widehat{C}_{n}, D^{*}().\right)$ and type $i$ individuals choose $\widehat{C}_{i}$. (13) means that there is full distribution of profit to policyholders (or additional premiums will be levied to cover losses if any) but from (15) threshold types $\ell_{\theta}$ are excluded from the sharing of profits.

From (14) no policy dividend is paid on the equilibrium path. However there may be policy dividends or supplementary premiums when a deviant insurer $j^{0}$ offers a

\footnotetext{
${ }^{24}$ Consider a randomized allocation which is feasible in $\mathbb{P}_{h}$ and replace it by another allocation without randomization where individuals choose (with probability 1) the most profitable lottery which they choose with positive probability in the initial lottery. By doing that, we relax the profit constraint and other constraints still hold in $\mathbb{P}_{h}$. This shows that individuals do not randomize at an optimal solution to $\mathbb{P}_{h}$. This argument is also used in the proof of Lemma 3 .
} 
menu $C^{j_{0}}$ of contracts that differs from $C^{*}=\left(\widehat{C}_{1}, \ldots, \widehat{C}_{n}\right)$. Indeed such a deviation may affect the types distribution of individuals who still choose a contract in $C^{*}$, with possible variations in profits or losses of other insurers $j \neq j_{0}$, and thus policy dividends or supplementary premiums. Variations in policy dividends can then act as an implicit threat that dissuades deviant insurers from undertaking competitive attacks. As an intuitive example to understand the logic of this threat, consider the following example:

$$
D_{i}^{*}\left(N_{1}, P_{1}, \ldots, N_{n}, P_{n}\right)=\frac{N_{i}\left(\widehat{k}_{i}-\widehat{k}_{\ell_{\theta+1}}\right)}{\sum_{h=\ell_{\theta}+1}^{\ell_{\theta+1}} N_{h}\left(\widehat{k}_{h}-\widehat{k}_{\ell_{\theta+1}}\right)} \sum_{h=\ell_{\theta}+1}^{\ell_{\theta+1}} N_{h} P_{h} \text { for all } i=1, \ldots, n
$$

for all $i \in\left\{\ell_{\theta}+1, \ldots, \ell_{\theta+1}\right\}$ and all $\theta \in\{0, \ldots, \bar{\theta}\}$.Here $D^{*}($.$) involves the sharing of$ profit within each subgroup $\theta=0, \ldots, \bar{\theta}$. The total profit made within subgroup $\theta$ is $\sum_{h=\ell_{\theta}+1}^{\ell_{\theta+1}} N_{h} P_{h}$. It is affected to policyholders within the same subgroup. Furthermore, according to the policy dividend rule, the larger the premium, the larger the (net) policy dividend. There is no right to receive policy dividend for the individuals who pay the smallest premium (i.e. for type $\ell_{\theta+1}$ ) while rights are larger for types $i$ who pay larger premiums. We have $\sum_{h=\ell_{\theta}+1}^{\ell_{\theta+1}} \lambda_{h} \Pi\left(\widehat{C}_{h}\right)=0$ for all $\theta$, and thus this policy dividend rule satisfies conditions (13)-(15).

If a deviant insurer $j_{0}$ attracts some individuals who cross-subsidize other risk types within subgroup $\theta$, then after the deviation we will have $\sum_{h=\ell_{\theta}+1}^{\ell_{\theta+1}} N_{h} P_{h}<0$ for non-deviant insurers $j \neq j_{0}$ and consequently the welfare of these other individuals will deteriorate if they keep choosing the same contract because they will have to pay supplementary premiums. It may then be impossible for insurer $j_{0}$ not to attract them also, which will make its offer non-profitable. The proof of Proposition 3 shows that this is indeed the case.

More generally, when $D^{*}($.$) is such that$

$$
\sum_{h=\ell_{\theta}+1}^{\ell_{\theta+1}} D_{h}^{*}\left(N_{1}, P_{1}, \ldots, N_{n}, P_{n}\right) \equiv \sum_{h=\ell_{\theta}+1}^{\ell_{\theta+1}} N_{h} P_{h}
$$

then the equilibrium allocation is also sustained by equilibrium strategies where each insurer sells insurance to a given subgroup of individuals (gathering risk types $h=$ 
$\left.\ell_{\theta}+1, \ldots, \ell_{\theta+1}\right)$ or to a combination of these subgroups. Insurers who sell insurance to subgroups with only one risk type (i.e. groups such that $\ell_{\theta}+1=\ell_{\theta+1}$ ) or to a combination of these subgroups do not cross-subsidize risks. They offer non-participating policies, and we may consider them as stock insurers. Insurers who sell insurance policies to subgroups with cross-subsidization (i.e. such that $\ell_{\theta}+1<\ell_{\theta+1}$ ) crosssubsidize risks and they offer participating policies with full distribution of profit to policyholders: they act as mutuals do. Hence, the model explain why stock insurers and mutuals may coexist : mutuals offer insurance contracts that are robust to competitive attacks when there is cross-susidization, while stock insurers offer insurance contracts at actuarial price.

\section{Deferred premium variations}

More often than not mutuals shift the payment of underwriting profit to their members by transferring current profit to reserves and by later increasing or decreasing premiums according to the level of accumulated surplus. Reserves then act act as a shock absorber and unforeseen supplementary calls occur only in case of large unexpected losses. Such deferred premium variations are substitutes to policy dividends and supplementary premiums paid or levied during the current period. They may have similar strategic effects, but they also entail specific dynamic issues that are more complex than the instantaneous contracting problem we have considered thus far. Although a comprehensive dynamic analysis is out of the scope of this paper, we may nevertheless sketch the similarities and differences between participating contracts and deferred premium variations.

Consider an overlapping generation setting in which each individual lives for two periods ( 1 and 2 ). Assume that money can be transferred costlessly over time with zero interest rate. Assume also that transaction costs prevent individuals from changing their insurers between periods 1 and 2, which is of course a very strong assumption. Type $i$ individuals suffer loss $A$ at each period of their life with probability $\pi_{i}$. Insurers offer intertemporal insurance contracts with variable premiums. Contractual agreements specify the net coverage $x$ in the case of an accident (be it at period 1 or 2 ). Premium may increase or decrease between periods 1 and 2 according to underwriting profits made at period 1 . Policyholders pay $k$ at period 1 and $k-D$ at period 2 , where $D$ depends on the profit made at period $1 . D$ is thus analogous to a policy dividend moved one period back ${ }^{25}$. For example, if the premium increase just covers the underwriting losses over the two periods, we should have $D=2 P$, where $P$ is the

\footnotetext{
${ }^{25}$ Experience rating (i.e. conditioning the premium paid at period 2 on the policyholder's loss experience at period 1) would improve the efficiency of market mechanisms. It is not considered here for notational simplicity.
} 
underwriting profit per period ${ }^{26}$

Since wealth can be transferred over time without cost, individuals maximize the expected utility of their cumulated final wealth, which is written as

$$
\begin{aligned}
E u= & (1-\pi)^{2} u\left(W_{N}-2 k+D\right) \\
& +2 \pi(1-\pi) u\left(W_{A 1}+x+D\right)+\pi^{2} u\left(W_{A 2}+2 x+D\right),
\end{aligned}
$$

where $W_{A 1}=W_{N}-A, W_{A 2}=W_{N}-2 A$ and $\pi=\pi_{i}$ for type $i$ individuals. An allocation is now written as $\left\{\left(W_{i}^{1}, W_{i 1}^{2}, W_{i 2}^{2}\right), i=1, \ldots, n\right\}$, where $W_{i}^{1}$ denotes the final wealth of type $i$ individuals who do not suffer any accident and $W_{i 1}^{2}$ (respect. $W_{i 2}^{2}$ ) is the final wealth in case of one accident (respect. two accidents), with

$$
\begin{aligned}
W_{i}^{1} & =W_{N}-2 k_{i}+D_{i}, \\
W_{i 1}^{2} & =W_{A 1}+x_{i}+D_{i}, \\
W_{i 2}^{2} & =W_{A 2}+2 x_{i}+D_{i},
\end{aligned}
$$

where $k_{i}, x_{i}$ and $D_{i}$ refer to the insurance contract chosen by type $i$ individuals.

The developments and conclusions of Section 4 can be straightforwardly adapted to this new setting, with unchanged definitions of reservation utility $\bar{u}_{i}$ and of the candidate equilibrium allocation $\left\{\left(\widehat{W}_{i}^{1}, \widehat{W}_{i 1}^{2}, \widehat{W}_{i 2}^{2}\right), i=1, \ldots, n\right\}^{27}$. This allocation is sustained by a subgame perfect Nash equilibrium of the market game where insurers offer intertemporal insurance contracts with variable premiums to each cohort of individuals who enter the market.

Matters would be much less obvious if individuals could move to another insurer between periods 1 and 2 . Indeed consider the two risk type case and assume that there is cross-subsidization at the candidate equilibrium. Then if a deviant insurer attracts low risk individuals at the first period of their life, thereby leading to underwriting losses for non-deviant insurers, then high risks may choose to quit only at period 2 in order to escape from the increase in premium. However, by doing that they would signal themselves as high risk (because low risks are attracted from period 1), which would reduce the advantage they may get from moving to another insurer. This signalling effect may lead high risk individuals either to move to the deviant insurer over the two periods of their life or not to move at all. Whether it is sufficient to annihilate competitive attacks remains an open issue.

\footnotetext{
${ }^{26}$ Note that profit remains constant across time for a given cohort since policyholders do not change insurers between the two periods of their life.

${ }^{27}$ Note in particular that the marginal rate of substitution between $x$ and $k$ is increasing with $\pi$ when $x \leq A$. Indifference curves thus cross only one time in this part of the $(x, k)$ plane, which implies that only upward adjacent incentive compatibility constraints are binding. The analysis of Section 4 can thus be replicated without substantial change.
} 


\section{Concluding comments}

The initial motivation of this paper was an inquiry on the nonexistence of equilibrium in the RS model, starting with the observation that this model restricts the set of insurance contracts to non-participating policies. The result of this inquiry is actually striking since it turns out that allowing insurers to offer participating policies guarantees the existence of an equilibrium in the RS model. The equilibrium allocation coincides with the MSW allocation. In the case of two groups of individuals, there is cross-subsidization between contracts when the proportion of high risks individuals is under a threshold, while the equilibrium allocation coincides with Rothschild-Stiglitz pair of contracts in the other case. In the general case with an arbitrary number of risk types, the equilibrium allocation is characterized by a classification of individuals into subgroups as done by Spence (1978), with cross-subsidization within each subgroup.

Participating policies act as an implicit threat which prevents deviant insurers to attract low risk individuals only. If a deviant insurer attracts individuals who crosssubsidize other risk types within a given subgroup, then these other individuals will have to pay supplementary premiums if they keep choosing the same contract from their non-deviant insurer. Consequently it will be impossible for the deviant insurer not to attract them also, which will make its offer non-profitable. This mechanism is similar to the logic of the MSW equilibrium. In both cases, a deviant insurer is detered to attract low risk individuals because it is expected that ultimately its offer would also attract higher risks, which would make it unprofitable. However, in the MSW equilibrium insurers are protected from these competitive attacks because they can react by withdrawing contracts that become unprofitable. This assumption is most unsatisfactory because it means that insurers are not committed to actually offer the announced contracts. It can also be legitimately argued that this description of the dynamic relationship between insurers is arbitrary. Other timings are possible, as shown by Riley (1979), Hellwig (1987) and others. The present model has not stepped away from the Nash equilibrium setting of the RS model, and we have just explored the consequences of deleting an exogenous restriction on the content of insurance policies.

More than the solution to a theoretical puzzle, the outcome of this inquiry on the extended RS model provides a new explanation about why mutuals are so widespread in insurance markets and why they coexist with stock insurers. Most explanations about why mutuals may be more efficient than stock insurers are either based on the reduction in agency costs made possible by the mutual corporate form (Mayers and Smith,1988; Smith and Stutzer,1995), on the fact that mutuals may emerge as a risk screening mechanism (Smith and Stutzer,1990; Ligon and Thistle,2005) or on their ability to cover undiversifiable risks (Doherty and Dionne,1993). This paper has explored a different way. Starting from the RS equilibrium puzzle, we finally came to the conclusion that mutuals endogenously emerge in a competitive setting when secondbest allocative efficiency requires cross-subsidization, while stock insurers can survive in the other cases. Comparing the empirical validity of these approaches remains an 
open issue. At this stage, the only conclusion we can draw is that mutuals are robust to competitive attacks in insurance markets characterized by adverse selection, which may not be the case for stock insurance companies.

\section{Appendix}

\section{Proof of Lemma 1}

If $\sum_{h=1}^{i} \lambda_{i}\left[W_{N}-\left(1-\pi_{i}\right) \widehat{W}_{i}^{1}-\pi_{i}\left(\widehat{W}_{i}^{2}+A\right)\right]>0$ for $i \in\{1, \ldots, n\}$, then it would be possible to provide a higher expected utility than $\bar{u}_{\ell}$ for all $\ell=1, \ldots, i$, while breaking even over the subset of individuals $\ell=1, \ldots, i$, which would contradict the definition of $\bar{u}_{i}$. We thus have $\sum_{h=1}^{i} \lambda_{i}\left[W_{N}-\left(1-\pi_{i}\right) \widehat{W}_{i}^{1}-\pi_{i}\left(\widehat{W}_{i}^{2}+A\right)\right] \leq 0$ for all $i \in\{1, \ldots, n\}$, which yields the first part of the Lemma.

We have $\left(1-\pi_{i}\right) u\left(\widehat{W}_{i}^{1}\right)+\pi_{i} u\left(\widehat{W}_{i}^{2}\right) \geq \bar{u}_{i}$ for all $i$ from the definition of $\mathbb{P}_{n}$. If $i \in\left\{\ell_{1}, \ell_{2}, \ldots, n\right\}$, we have $\sum_{h=1}^{i} \lambda_{h}\left[\left(1-\pi_{h}\right) \widehat{W}_{h}^{1}+\pi_{h}\left(\widehat{W}_{h}^{2}+A\right)\right]=W_{N}$ from the first part of the Lemma and we deduce $\left(1-\pi_{i}\right) u\left(\widehat{W}_{i}^{1}\right)+\pi_{i} u\left(\widehat{W}_{i}^{2}\right)=\bar{u}_{i}$, for otherwise we would have a contradiction with the definition of $\bar{u}_{i}$. Conversely, suppose we have $(1-$ $\left.\pi_{i}\right) u\left(\widehat{W}_{i}^{1}\right)+\pi_{i} u\left(\widehat{W}_{i}^{2}\right)=\bar{u}_{i}$ and $i \notin\left\{\ell_{1}, \ell_{2}, \ldots, n\right\}$. We would then have $\sum_{h=1}^{i} \lambda_{h}\left[W_{N}-\right.$ $\left.\left(1-\pi_{h}\right) \widehat{W}_{h}^{1}-\pi_{h}\left(\widehat{W}_{h}^{2}+A\right)\right]<0$. Hence the allocation $\left\{\left(\widehat{W}_{h}^{1}, \widehat{W}_{h}^{2}\right), h=1, \ldots, i\right\}$ is in deficit. Let $\left\{\left(W_{h}^{1 \prime}, W_{h}^{2 \prime}\right), h=1, \ldots, i\right\}$ be the optimal solution to $\mathbb{P}_{i}$. Replacing $\left\{\left(\widehat{W}_{h}^{1}, \widehat{W}_{h}^{2}\right), h=1, \ldots, i\right\}$ by $\left\{\left(W_{h}^{1 \prime}, W_{h}^{2 \prime}\right), h=1, \ldots, i\right\}$ allows us to improve the optimal solution to $\mathbb{P}_{n}$, since the same type $i$ expected utility $\bar{u}_{i}$ can be reached while breaking even on the set $h=1, \ldots, i$, which provides additional resources that could be used to raise $\left(1-\pi_{n}\right) u\left(W_{n}^{1}\right)+\pi_{n} u\left(W_{n}^{2}\right)$ over $\left(1-\pi_{n}\right) u\left(\widehat{W}_{n}^{1}\right)+\pi_{n} u\left(\widehat{W}_{n}^{2}\right)$. We thus obtain a contradiction with the fact that $\left\{\left(\widehat{W}_{i}^{1}, \widehat{W}_{i}^{2}\right), i=1, \ldots, n\right\}$ is the optimal solution to $\mathbb{P}_{n}$.

\section{Proof of Lemma 2}

We first restrict attention to incentive compatible allocations $\left\{\left(W_{h}^{1}, W_{h}^{2}\right), h=\right.$ $1, \ldots, n\}$ located in a neighbourhood of $\left\{\left(\widehat{W}_{h}^{1}, \widehat{W}_{h}^{2}\right), i=1, \ldots, n\right\}$. Suppose that such an allocation satisfies (9)-(10). Lemma 1 shows that

$$
\left(1-\pi_{h}\right) u\left(W_{h}^{1}\right)+\pi_{h} u\left(W_{h}^{2}\right) \geq \bar{u}_{h} \text { for all } h=1, \ldots, n,
$$

if $\left(W_{h}^{1}, W_{h}^{2}\right)$ is close enough to $\left(\widehat{W}_{h}^{1}, \widehat{W}_{h}^{2}\right)$. Hence $\left\{\left(W_{h}^{1}, W_{h}^{2}\right), h=1, \ldots, n\right\}$ satisfies the constraints of $\mathbb{P}_{n}$ for $h=1, \ldots, i$ with positive profits and expected utility larger or equal to $\bar{u}_{n}$ for type $n$, hence a contradiction.

We now prove that there does not exist any incentive compatible allocation $\left\{\left(W_{h}^{1}, W_{h}^{2}\right), h=1, \ldots, n\right\}$ that satisfies (9)-(10) even if we do not restrict attention to allocations close to $\left\{\left(\widehat{W}_{h}^{1}, \widehat{W}_{h}^{2}\right), i=1, \ldots, n\right\}$. Let us define

$$
\begin{aligned}
q_{h} & \equiv \frac{1-\pi_{h}}{\pi_{h}} u\left(W_{h}^{1}\right), z_{h} \equiv u\left(W_{h}^{2}\right) \\
\widehat{q}_{h} & \equiv \frac{1-\pi_{h}}{\pi_{h}} u\left(\widehat{W}_{h}^{1}\right), \widehat{z}_{h} \equiv u\left(\widehat{W}_{h}^{2}\right) .
\end{aligned}
$$


With this change of variable the Lemma states that there does not exist $\left\{\left(q_{h}, z_{h}\right), h=\right.$ $1, \ldots, n\}$ such that

$$
\begin{aligned}
& q_{\ell_{\theta}}+z_{\ell_{\theta}} \geq \frac{\bar{u}_{\ell_{\theta}}}{\pi_{\ell_{\theta}}} \text { for all } \theta=1, \ldots, \bar{\theta}+1, \\
& q_{h}+z_{h} \geq \frac{1-\pi_{h}}{\pi_{h}} \frac{\pi_{h+1}}{1-\pi_{h+1}} q_{h+1}+z_{h+1} \text { for } h=1, \ldots, n-1, \\
& \sum_{h=1}^{n} \lambda_{h}\left\{\left(1-\pi_{h}\right)\left[W_{N}-u^{-1}\left(\frac{\pi_{h} q_{h}}{1-\pi_{h}}\right)\right]-\pi_{h}\left[u^{-1}\left(z_{h}\right)-W_{A}\right]\right\} \\
& >\sum_{h=1}^{n} \lambda_{h}\left\{\left(1-\pi_{h}\right)\left[W_{N}-u^{-1}\left(\frac{\pi_{h} \widehat{q}_{h}}{1-\pi_{h}}\right)\right]-\pi_{h}\left[u^{-1}\left(\widehat{z}_{h}\right)-W_{A}\right]\right\} .
\end{aligned}
$$

The set of $\left\{q_{h}, z_{h}, h=1, \ldots, n\right\}$ that satisfies the conditions (18)-(20) is convex ${ }^{28}$. Hence if there is any allocation $\left\{q_{h}, z_{h}, h=1, \ldots, n\right\}$ that satisfies conditions (18)-(20), there is an allocation in any neighbourhood of $\left\{\widehat{q}_{h}, \widehat{z}_{h}, h=1, \ldots, n\right\}$ that satisfies them, which contradicts our previous result.

\section{Proof of Lemma 3}

For a given incentive compatible allocation with randomisation $\left\{\left(W_{s}^{1}, W_{s}^{2}\right), s=\right.$ $\left.1, \ldots, N ; \sigma \equiv\left(\sigma_{1}, \sigma_{2}, \ldots, \sigma_{n}\right)\right\}$, let $\left(\bar{W}_{h}^{1}, \bar{W}_{h}^{2}\right)=\left(W_{s(h)}^{1}, W_{s(h)}^{2}\right)$ be the most profitable lottery which is chosen by type $h$ individuals with positive probability, i.e. $s(h)$ is such that $\sigma_{h, s(h)}>0$ and

$$
\left(1-\pi_{h}\right) W_{s(h)}^{1}+\pi_{h} W_{s(h)}^{2} W_{s(h)}^{2} \leq\left(1-\pi_{h}\right) W_{s^{\prime}}^{1}+\pi_{h} W_{s^{\prime}}^{2}
$$

for all $s^{\prime}$ such that $\sigma_{h, s^{\prime}}>0$. If (11)-(12) hold for the initial allocation with randomization, then (9)-(10) also hold for the non-randomized incentive compatible allocation $\left\{\left(\bar{W}_{h}^{1}, \bar{W}_{h}^{2}\right), h=1, \ldots, n\right\}$, which contradicts Lemma 2 .

\section{Proof of Proposition 3}

Assume that each insurer offers $\widehat{C}=\left(\widehat{C}_{1}, \widehat{C}_{2}, \ldots, \widehat{C}_{n}, D^{*}().\right)$ with $D^{*}($.$) such that$ (13)-(15) hold. Then $\widehat{C}_{i}$ is an optimal choice of type $i$ individuals if they expect that no policy dividend will be paid on any contract. When all individuals are evenly shared among insurers, then (14) implies that no policy dividend is actually paid.

Suppose some insurer $j_{0}$ deviates from $\widehat{C}$ to another menu $C^{j_{0}}=\left\{C_{1}^{j_{0}}, C_{2}^{j_{0}}, \ldots, C_{n}^{j_{0}}, D^{j_{0}}().\right\}$ with $C_{i}^{j_{0}}=\left(k_{i}^{j_{0}}, x_{i}^{j_{0}}\right)$. Let $\widetilde{\sigma}\left(C^{j_{0}}, \widehat{C}^{-j_{0}}\right)$ be a continuation equilibrium following the deviation, i.e. equilibrium contract choices by individuals when $C^{j_{0}}$ and $\widehat{C}$ are simultaneously offered, respectively by insurer $j_{0}$ and by all the other insurers $j \neq j_{0}$. Such a continuation equilibrium exists since it is a mixed-strategy equilibrium of a finite

\footnotetext{
${ }^{28}$ Note in particular that $u^{-1}($.$) is convex because u($.$) is concave.$
} 
strategic-form game. Let $\bar{P}_{h}^{j}$ be the profit per policyholder made by insurer $j \neq j_{0}$ on contract $\widehat{C}_{h}$ and $\bar{N}_{h}^{j}$ be the proportion of the population who is purchasing $\widehat{C}_{h}$ from insurer $j$ at such a continuation equilibrium, i.e.

$$
\begin{aligned}
\bar{P}_{h}^{j} & \equiv \frac{\sum_{i=1}^{n} \lambda_{i} \widetilde{\sigma}_{i h}^{j}\left(C^{j_{0}}, \widehat{C}^{-j_{0}}\right) \Pi_{i}\left(\widehat{C}_{h}\right)}{\sum_{i=1}^{n} \lambda_{i} \widetilde{\sigma}_{i h}^{j}\left(C^{j_{0}}, \widehat{C}^{-j_{0}}\right)}, \\
\bar{N}_{h}^{j} & =\sum_{i=1}^{n} \lambda_{i} \widetilde{\sigma}_{i h}^{j}\left(C^{j_{0}}, \widehat{C}^{-j_{0}}\right) .
\end{aligned}
$$

Choose each $D^{j}($.$) so that D_{h}^{j}($.$) is homogeneous of degree 1$ with respect to $\left(N_{1}^{j}, \ldots, N_{n}^{j}\right)$ for all $h=1, \ldots, n$ and consider a continuation equilibrium where individuals of a given type are evenly shared between insurers $j \neq j_{0}$, i.e. where $\widetilde{\sigma}_{i h}^{j}\left(C^{j_{0}}, \widehat{C}^{-j_{0}}\right)=$ $\widetilde{\sigma}_{i h}^{j^{\prime}}\left(C^{j_{0}}, \widehat{C}^{-j_{0}}\right)$ for all $h$ if $j \neq j^{\prime}, j, j^{\prime} \neq j_{0}{ }^{29}$. We may then use more compact notations $\widetilde{\sigma}_{i h}^{0} \equiv \widetilde{\sigma}_{i h}^{j_{0}}\left(C^{j_{0}}, \widehat{C}^{-j_{0}}\right)$ and $\widetilde{\sigma}_{i h}^{1} \equiv \widetilde{\sigma}_{i h}^{j}\left(C^{j_{0}}, \widehat{C}^{-j_{0}}\right), \bar{P}_{h}^{1}=\bar{P}_{h}^{j}, \bar{N}_{h}^{1}=\bar{N}_{h}^{j}$ for all $j \neq j_{0}$. Let also

$$
\begin{aligned}
\bar{P}_{h}^{0} \equiv & \frac{\sum_{i=1}^{n} \lambda_{i} \widetilde{\sigma}_{i h}^{j_{0}}\left(C^{j_{0}}, \widehat{C}^{-j_{0}}\right) \Pi_{i}\left(C_{h}^{j_{0}}\right)}{\sum_{i=1}^{n} \lambda_{i} \widetilde{\sigma}_{i h}^{j_{0}}\left(C^{j_{0}}, \widehat{C}^{-j_{0}}\right)} \\
\bar{N}_{h}^{0} & =\sum_{i=1}^{n} \lambda_{i} \widetilde{\sigma}_{i h}^{j_{0}}\left(C^{j_{0}}, \widehat{C}^{-j_{0}}\right)
\end{aligned}
$$

denote respectively the average profit made on $C_{h}^{j_{0}}$ by insurer $j_{0}$ and the proportion of individuals who choose $\mathcal{C}_{h}^{j_{0}}$. Hence, after the deviation by insurer $j_{0}$, type $i$ individuals get the following lottery on final wealth :

$$
\begin{aligned}
& \left(W^{1}, W^{2}\right)=\left(W_{0 h}^{1}, W_{0 h}^{2}\right) \equiv\left(W_{N}-k_{h}^{j_{0}}+\bar{D}_{h}^{0}, W_{A}+x_{h}^{j_{0}}+\bar{D}_{h}^{0}\right) \text { with probability } \widetilde{\sigma}_{i h}^{0}, \\
& \left(W^{1}, W^{2}\right)=\left(W_{1 h}^{1}, W_{1 h}^{2}\right) \equiv\left(\widehat{W}_{h}^{1}+\bar{D}_{h}^{1}, \widehat{W}_{h}^{2}+\bar{D}_{h}^{1}\right) \text { with probability } \widetilde{\sigma}_{i h}^{1}(n-1)
\end{aligned}
$$

where

$$
\begin{aligned}
& \bar{D}_{h}^{0}=D_{h}^{j_{0}}\left(\bar{N}_{1}^{0}, \bar{P}_{1}^{0}, \ldots, \bar{N}_{n}^{0}, \bar{P}_{n}^{0}\right), \\
& \bar{D}_{h}^{1}=D_{h}^{*}\left(\bar{N}_{1}^{1}, \bar{P}_{1}^{1}, \ldots, \bar{N}_{n}^{1}, \bar{P}_{n}^{1}\right),
\end{aligned}
$$

\footnotetext{
${ }^{29}$ Such a continuation equilibrium exists because it is a Nash equilibrium of an equivalent game with only two insurers that respectively offer $\widehat{C}^{-j_{0}}$ and $C^{j_{0}}$. Note that this equivalence is possible because $D_{h}^{j}($.$) is homogeneous of degree 1$ with respect to $\left(N_{1}^{j}, \ldots, N_{n}^{j}\right)$.
} 
for $h=1, \ldots, n$, with $\sum_{h=1}^{n}\left[\widetilde{\sigma}_{i h}^{0}+\widetilde{\sigma}_{i h}^{1}(n-1)\right]=1$. Let us denote this lottery by $\mathcal{L}$.

Let $\Delta$ denote the residual profit made by insurer $j_{0}$. We have

$$
\Delta=\sum_{i=1}^{n} \lambda_{i}\left\{\sum_{h=1}^{n} \widetilde{\sigma}_{i h}^{0}\left[W_{N}-\left(1-\pi_{i}\right) W_{0 h}^{1}-\pi_{i}\left(W_{0 h}^{2}+A\right)\right]\right\} .
$$

We know from (13) that $D^{*}($.$) involves the full distribution of profit. Hence non-$ deviant insurers $j$ make zero residual profit. We thus have

$$
\sum_{i=1}^{n} \lambda_{i}\left\{\sum_{h=1}^{n} \widetilde{\sigma}_{i h}^{1}\left[W_{N}-\left(1-\pi_{i}\right) W_{1 h}^{1}-\pi_{i}\left(W_{1 h}^{2}+A\right)\right]\right\}=0
$$

Adding (21) to (22) multiplied by $n-1$ yields

$$
\begin{aligned}
\Delta= & \sum_{i=1}^{n} \lambda_{i}\left\{\sum_{h=1}^{n} \widetilde{\sigma}_{i h}^{0}\left[W_{N}-\left(1-\pi_{i}\right) W_{0 h}^{1}-\pi_{i}\left(W_{0 h}^{2}+A\right)\right]\right. \\
& \left.+(n-1) \sum_{h=1}^{n} \tilde{\sigma}_{i h}^{1}\left[W_{N}-\left(1-\pi_{i}\right) W_{1 h}^{1}-\pi_{i}\left(W_{1 h}^{2}+A\right)\right]\right\} .
\end{aligned}
$$

Furthermore, we have

$$
\begin{aligned}
& \sum_{h=1}^{n} \widetilde{\sigma}_{\ell_{\theta}, h}^{0}\left[\left(1-\pi_{\ell_{\theta}}\right) u\left(W_{0 h}^{1}\right)+\pi_{\ell_{\theta}} u\left(W_{0 h}^{2}\right)\right] \\
& +(n-1) \sum_{h=1}^{n} \widetilde{\sigma}_{\ell_{\theta}, h}^{1}\left[\left(1-\pi_{\ell_{\theta}}\right) u\left(W_{1 h}^{1}\right)+\pi_{\ell_{\theta}} u\left(W_{1 h}^{2}\right)\right. \\
\geq & \bar{u}_{\ell_{\theta}} \text { for all } \theta=1, \ldots, \bar{\theta}+1
\end{aligned}
$$

because $\left(W_{1 \ell_{\theta}}^{1}, W_{1 \ell_{\theta}}^{2}\right)=\left(\widehat{W}_{1 \ell_{\theta}}^{1}, \widehat{W}_{1 \ell_{\theta}}^{2}\right)$ since $\bar{D}_{\ell_{\theta}}^{1}=0$ from $(15)$ and $\left(1-\pi_{\ell_{\theta}}\right) u\left(\widehat{W}_{1 \ell_{\theta}}^{1}\right)+$ $\pi_{\ell_{\theta}} u\left(\widehat{W}_{1 \ell_{\theta}}^{2}\right)=\bar{u}_{\ell_{\theta}}$ and $\left\{\widetilde{\sigma}_{\ell_{\theta}, h}^{0}, \widetilde{\sigma}_{\ell_{\theta}, h}^{1}, h=1, \ldots, n\right\}$ is an optimal contract choice strategy of type $\ell_{\theta}$ individuals. Lemma 3 applied to lottery $\mathcal{L}$ then gives $\Delta \leq 0$. Hence the deviation is non-profitable, which completes the proof.

\section{References}

Boyd, J.H., .C. Prescott and B.D. Smith, 1988, "Organizations in economic analysis", Canadian Journal of Economics,21, 477-491.

Crocker, K.J. and A. Snow, 1985, "The efficiency of competitive equilibria in insurance markets with asymmetric information", Journal of Public Economics, 26:2, 207-220. 
Doherty, N.A. and G. Dionne, 1993, "Insurance with undiversifiable risk : contract structure and organizational forms of insurance firms", Journal of Risk and Uncertainty, 6, 187-203.

Engers, M. and L. Fernandez, 1987, "Market equilibrium with hidden knowledge and self selection", Econometrica, 55, 425-439.

Hellwig, M., 1987, "Some recent developments in the theory of competition in markets with adverse selection", European Economic Review, 31, 319-325.

Ligon, J. A. and P.D. Thistle, 2005, "The formation of mutual insurers in markets with adverse selection, Journal of Business, 78, 529-555.

Mayers, D. and C. Smith, 1988, "Ownership structure accross lines of propertycasualty insurance", Journal of Law and Economics, 31, 351-378.

Miyazaki, H., 1977, "The rat race and internal labor markets", Bell Journal of Economics, 8, 394-418.

Riley, J., 1979, "Informational equilibrium", Econometrica, 47, 331-359.

Rothschild, M. and J.E. Stiglitz, 1976, "Equilibrium in competitive insurance markets: an essay on the economics of imperfect information", Quartely Journal of Economics, 90, 630-649.

Smith, B.D. and M.J. Stutzer, 1990, "Adverse selection, aggregate uncertainty and the role for mutual insurance contracts, Journal of Business, 63, 493-510.

Smith, B.D. and M.J. Stutzer, 1995, "A theory of mutual formation and moral hazard with evidence from the history of the insurance industry", Review of Economic Studies, 8, 545-577, 1995.

Spence, M., 1978, "Product differentiation and performance in insurance markets", Journal of Public Economics, 10, 427-447.

Wilson, C., 1977, "A model of insurance markets with incomplete information", Journal of Economic Theory, 16, 167-207. 


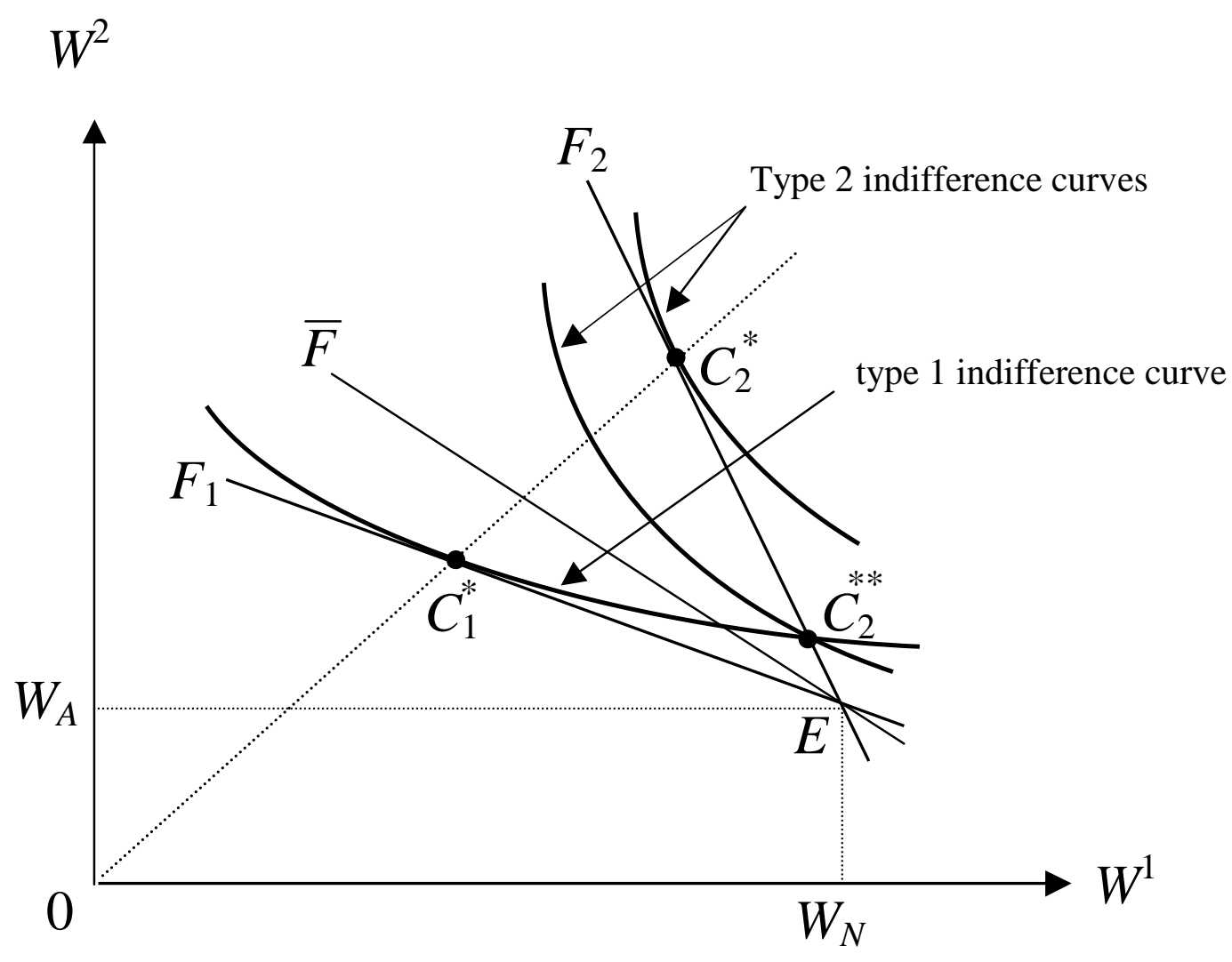

Figure 1 


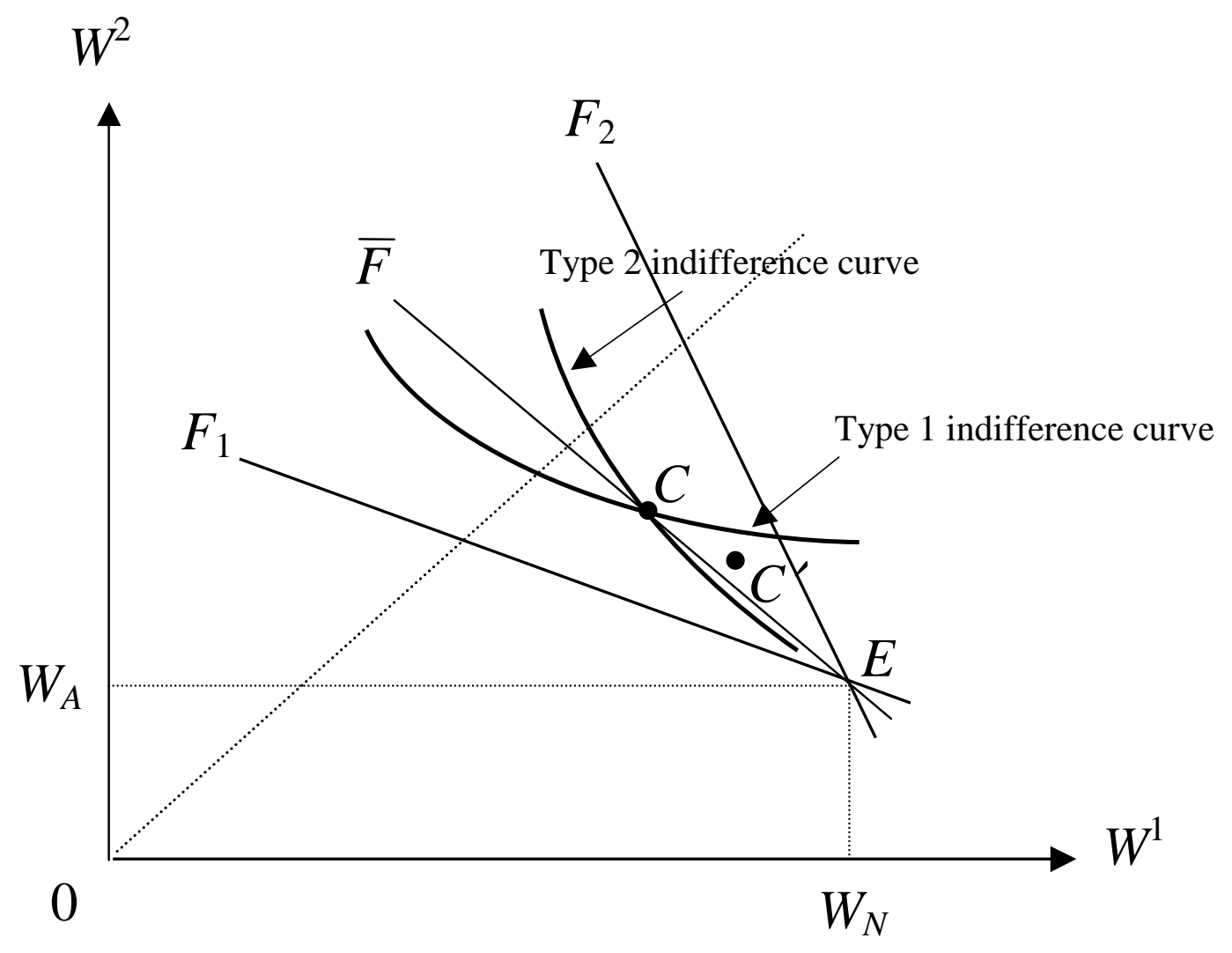

Figure 2 


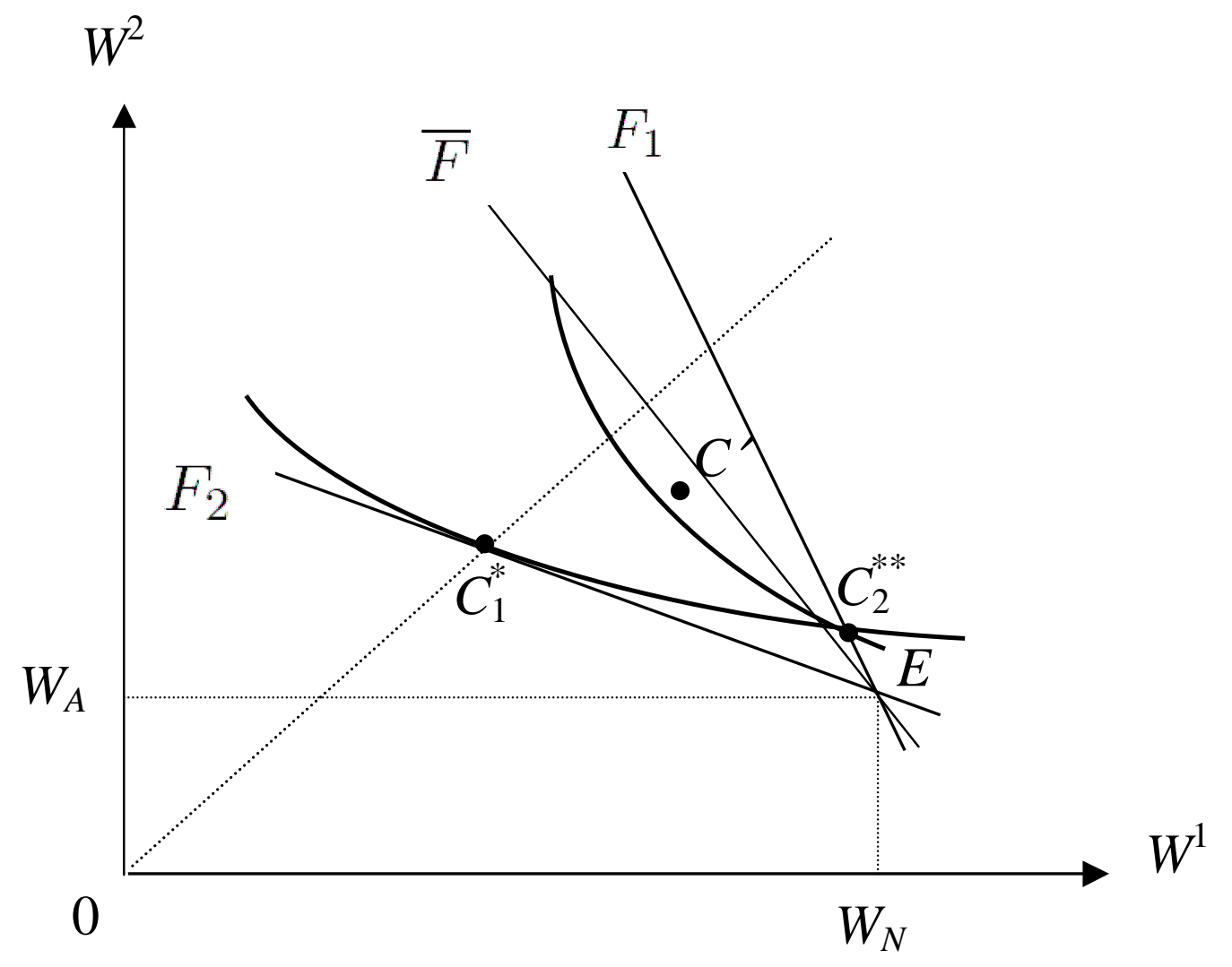

Figure 3 


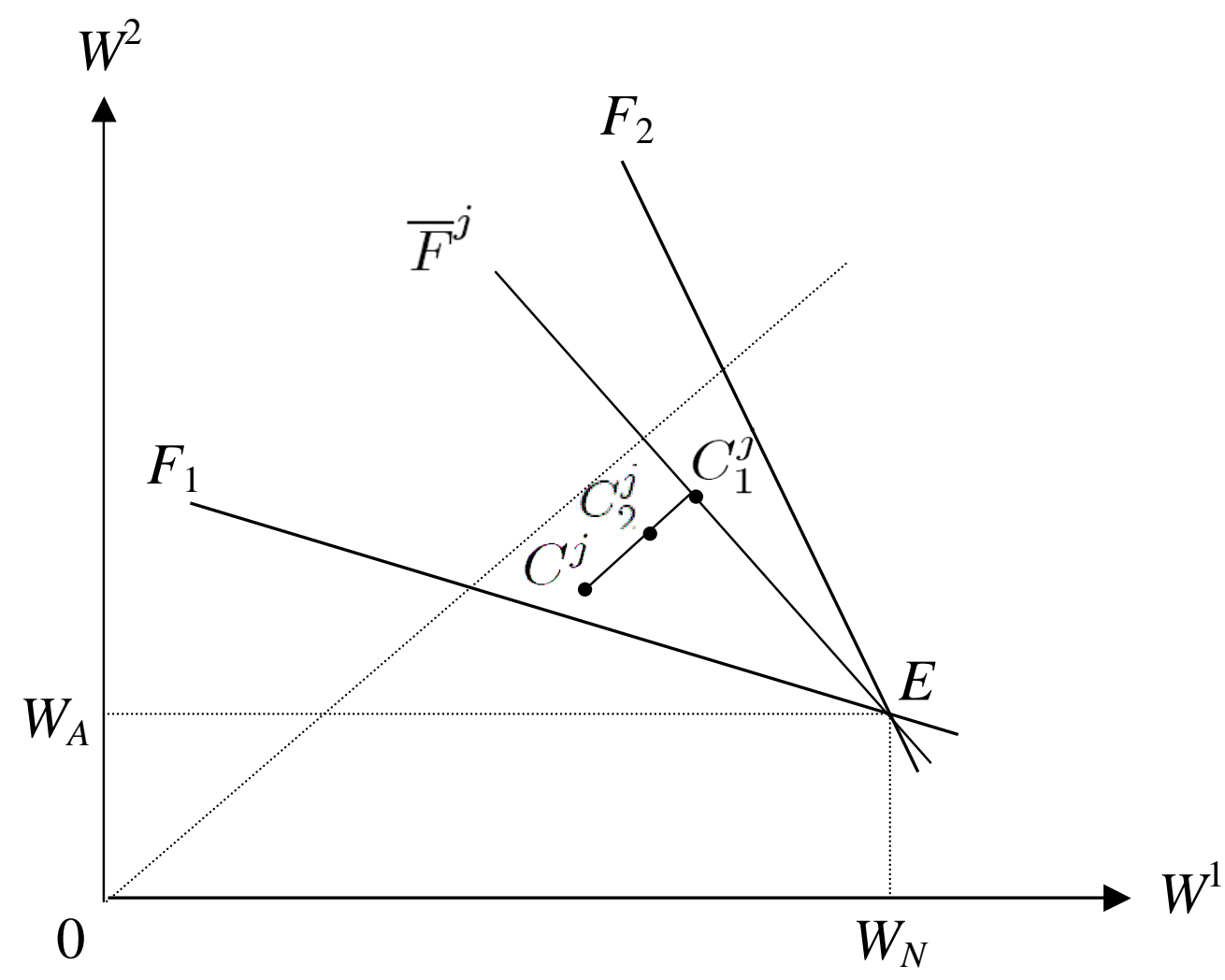

Figure 4 


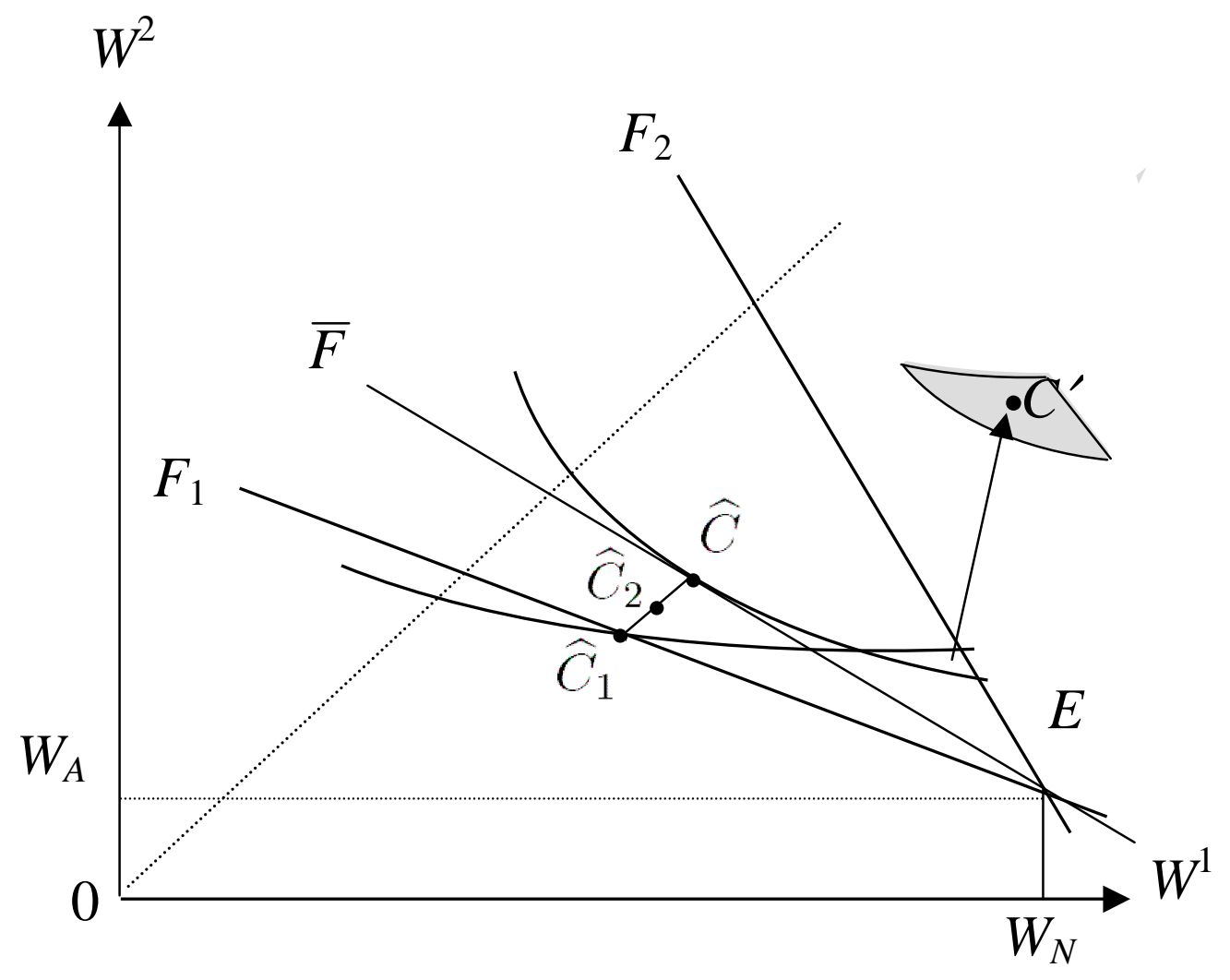

Figure 5 


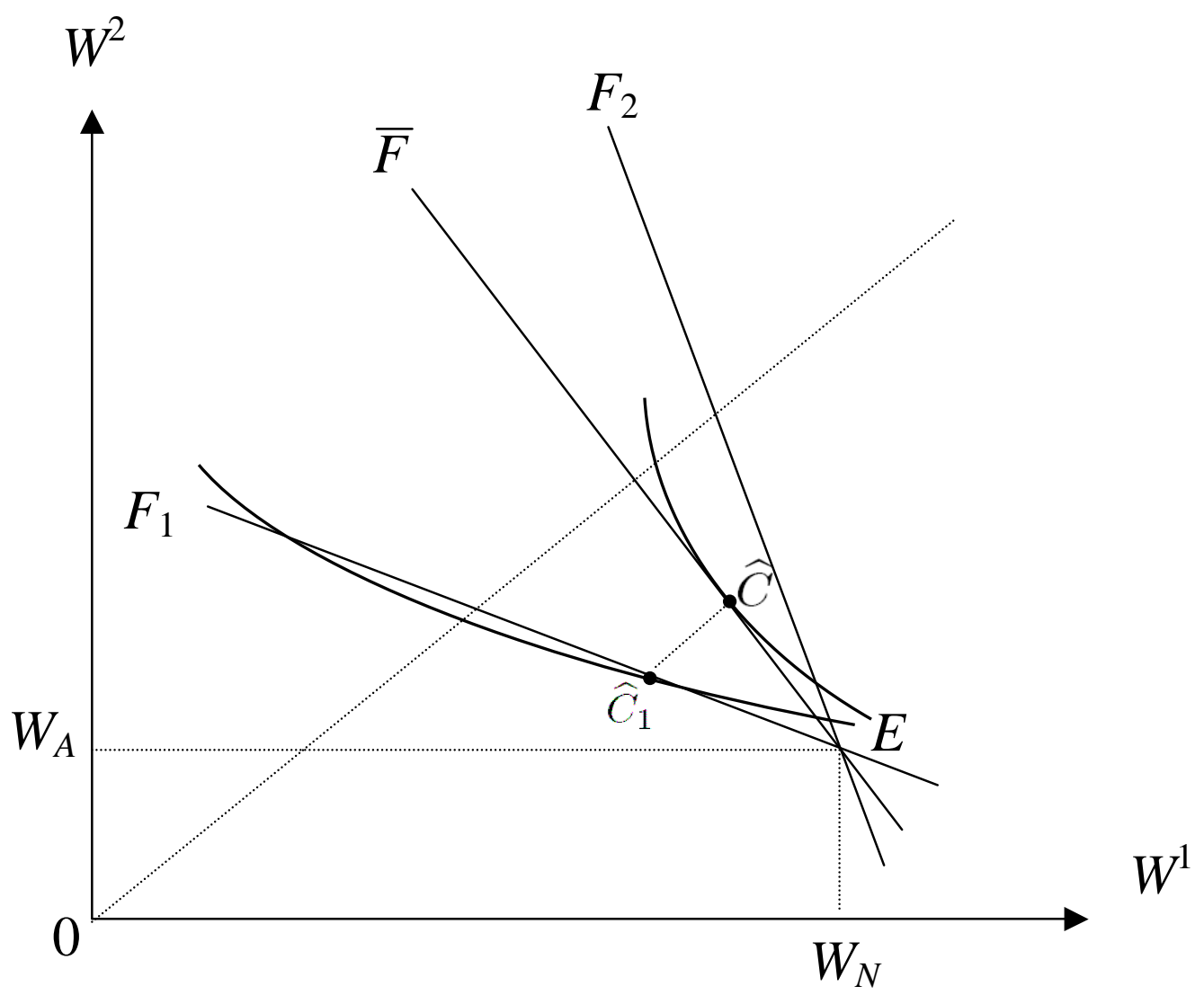

Figure 6 


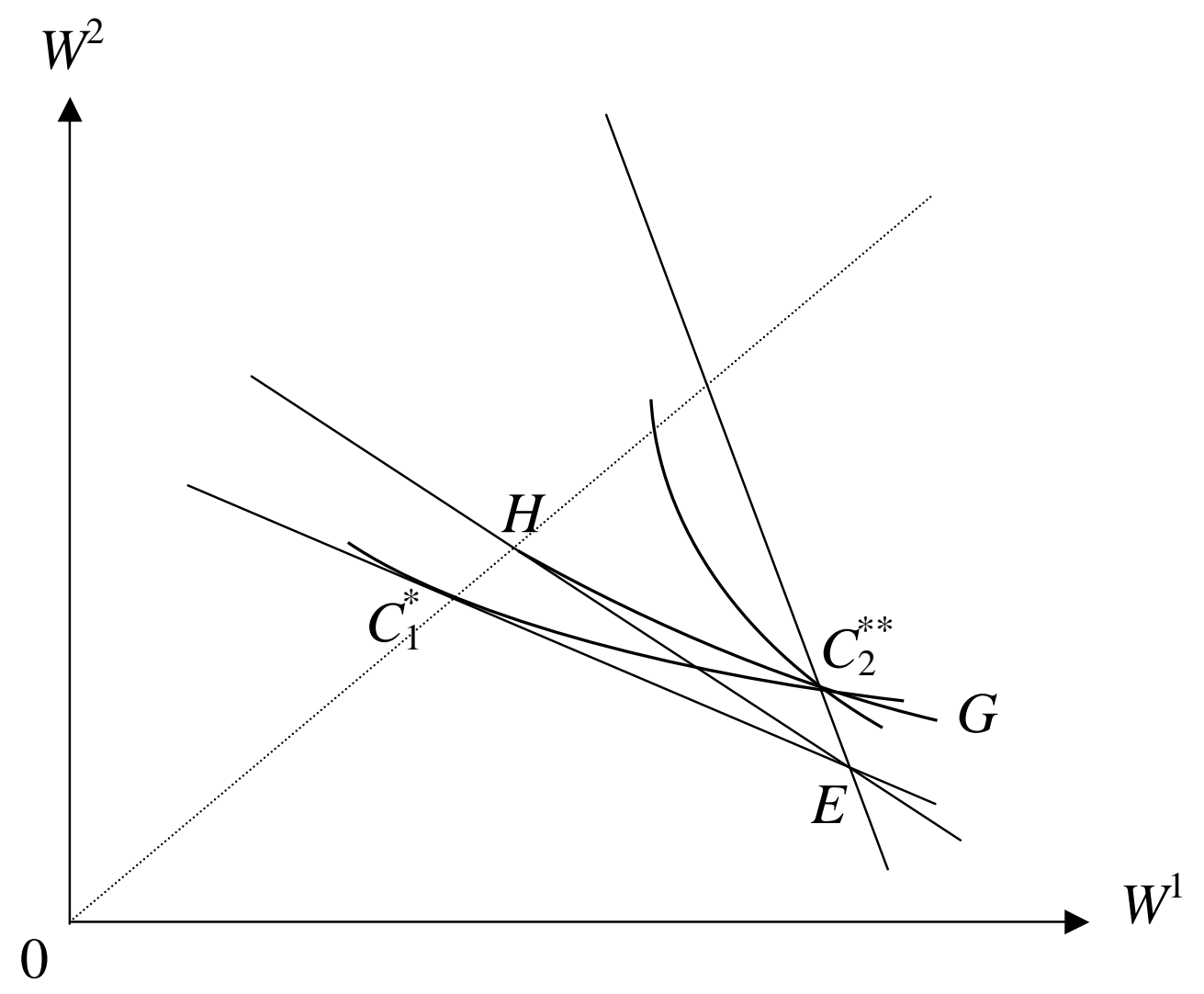

Figure 7 


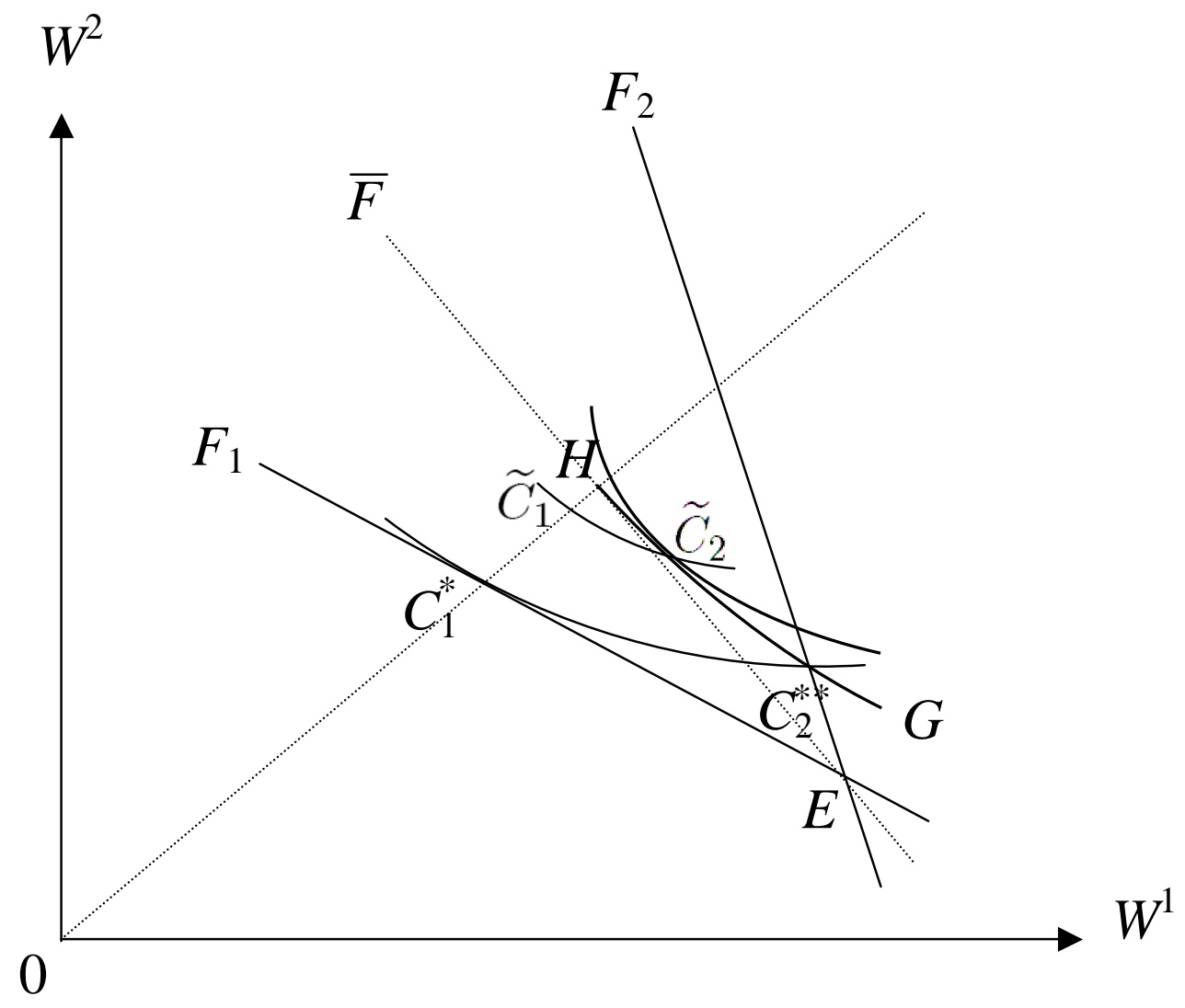

Figure 8 


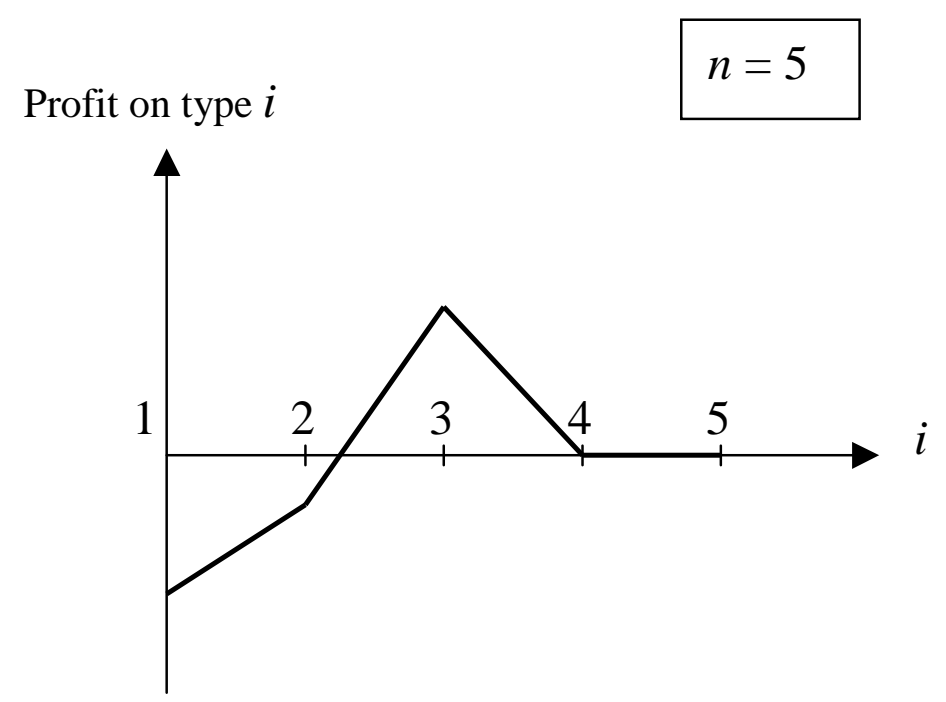

Figure 9 